\title{
The Rise of Single-Ion Magnets as Spin Qubits
}

\author{
You-Song Ding, Yi-Fei Deng and Yan-Zhen Zheng * \\ Frontier Institute of Science and Technology (FIST), State Key Laboratory of Mechanical Behavior of Materials \\ and MOE Key Laboratory for Nonequilibrium Synthesis and Modulation of Condensed Matter, \\ Xi'an Jiaotong University, Xi'an 710054, China; ding.you.song@stu.xjtu.edu.cn (Y.-S.D.); \\ chemaxiaoxifeng@stu.xjtu.edu.cn (Y.-F.D.) \\ * Correspondence: zheng.yanzhen@xjtu.edu.cn; Tel.: +86-29-8339-5366 \\ Academic Editor: Floriana Tuna \\ Received: 31 August 2016; Accepted: 25 October 2016; Published: 16 November 2016
}

\begin{abstract}
Recent studies revealed that magnetic molecules with single spin centers showed exciting phenomena related to quantum information processing, such as long quantum coherence times and Rabi oscillations. In this review, we go over these phenomena according to the essential metal ions, from which we can see the development of single-ion magnets as spin qubits is booming, especially quantum coherence times have been significantly enhanced from nanoseconds to hundreds of microseconds in a short period. Hence, the correlations between the molecular structures and quantum coherence are becoming clearer. In this regard, some chemical approaches to designing better spin qubits have been discussed.
\end{abstract}

Keywords: single-ion magnet; spin qubit; quantum coherence; quantum information processing

\section{Introduction}

Single-ion magnets (SIMs) are a kind of molecular magnets that contain only one spin center surrounded by organic ligands [1-5], and show potential applications for high-density information storage, molecular spintronic devices and quantum information processing (QIP) units [6-9]. In this review, we will focus on the topic of SIMs for QIP applications.

For classical computation, the data are encoded in binary digits (bits), each of which is a well-defined state $(0$ or 1$)$. In contrast, qubits take the advantage of superposition of quantum microstates. The basic set for qubits is $|\psi\rangle=\alpha|0\rangle+\beta|1\rangle$. Hence, a qubit can be either $|1\rangle$ or $|0\rangle$, or any arbitrary superposition of these two states [10-12]. The key point for being a good qubit is to have long transverse relaxation time $T_{2}$. Moreover, the spin-lattice relaxation time $T_{1}$, which describes transitions from, say, $|1\rangle$ to $|0\rangle$, is also very important because to observe the Rabi oscillations both $T_{1}$ and $T_{2}$ must be long enough. Because the period of coherent Rabi oscillations $1 / \Omega_{R}$, induced by an external stimulus (usually microwaves) between different qubit states, is actually used to evaluate the quality of a quantum system, the coherence time divided by half of the Rabi period, which is defined as $Q_{M}=2 \Omega_{R} T_{2}$ ( $Q_{M}$ is the qubit figure of merit) and represented by the number of coherent single-qubit operations, is useful to evaluate the performance of spin qubit. Only when the $Q_{M}$ is large enough, can the material then be used for QIP [13]. Other than the long coherence times, the possibility of building quantum logical gates is also very important [14].

Up to date, suitable physical carriers for qubits are found in ion traps [15,16], photons [17], nuclear spins [18], superconducting circuits [19,20], spin-based systems [21], atomic impurities in solids [22,23] and coordination molecules [12,24-27]. Among those candidates, the coordination molecules are extremely exciting due to the ready chemical design and detailed magneto-structural correlations. Specifically, the primary factors influencing the quantum decoherence such as the magnitude of spins, spin-orbit coupling effects and nuclear spin bath, and other peripheral factors such as the donor atoms of the coordinating ligands and solvent molecules can be systematically clarified, which can 
in turn guide the design of better molecular qubits [28-34]. Previously, such examples were only demonstrated by molecules with multi-metal centers [12,34]. More recently, new systems based on single-ion magnetic molecules were identified with even better performance owing to the well isolated environment. More excitingly, quantum logic gates such as the Controlled-NOT (CNOT) gate based on multiqubit can be readily achieved by chemical linkage of molecules [35-38] and quantum state can be read out by a single nuclear spin in $\mathrm{TbPc}_{2}[39,40]$. Here below, we discussed these exciting topics according to the comprising metal centers, highlighting their advantages for QIP applications.

\section{Single-Ion Magnetic Molecules with Transition Metal Centers}

As the valence electrons for $3 \mathrm{~d}$ transition metals locate in outer $\mathrm{d}$ orbits, the ligands coordinating to the transition metals have great impact on the electronic structure of the central cations, which then significantly influence the property of quantum coherence. The story starts from the simplest spin- $1 / 2$ systems such as $\mathrm{V}(\mathrm{IV})$ and $\mathrm{Cu}(\mathrm{II})$ ions with only two-level states, spin-up and spin-down.

\subsection{V(IV) Based Spin Qubits}

Pioneering work searching for potential spin qubits started from the $V(I V)$ ion with small spin- $1 / 2$ state and large nuclear spin $I=7 / 2$ (see Table 1). The first example is the complex $\left(\mathrm{Bu}_{4} \mathrm{~N}\right)_{2}\left[\mathrm{~V}\left(\mathrm{C}_{8} \mathrm{~S}_{8}\right)_{3}\right]$ $\mathbf{1}$ [41], in which the $\mathrm{V}(\mathrm{IV})$ ion is coordinated to six $\mathrm{S}$ ions, providing a nuclear spin free peripheral environment (Figure 1a). The hyperfine coupling of the electron spin and nuclear spin produces multiple states detected by electron paramagnetic resonance (EPR) spectrum (Figure 1b). Eight separate transitions were found to be potentially available for quantum information processing. The coherence time $T_{2}$ is $1.2 \mu \mathrm{s}$ at $80 \mathrm{~K}$ (performed on a $1 \mathrm{mM}$ solution of $\mathbf{1}$ in butyronitrile). Rabi oscillations are observed by transient nutation experiments (Figure 1d), and the Rabi frequencies yielded from the nutation data at 3486 Oe at corresponding microwave power $\left(B_{1}\right)$ attenuations, namely are $28.1 \mathrm{MHz}$, 17.6 MHz, and $10.2 \mathrm{MHz}$ for $3 \mathrm{~dB}, 7 \mathrm{~dB}$, and $11 \mathrm{~dB}$.

a
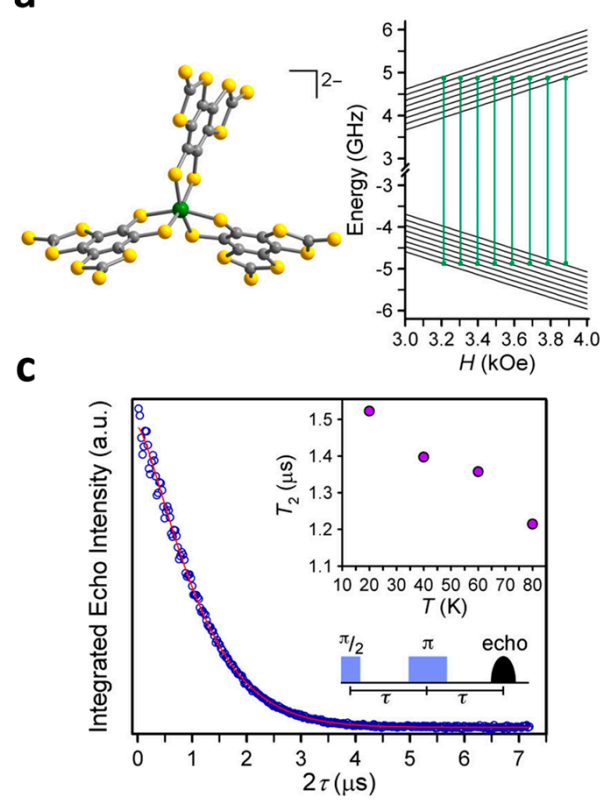

b

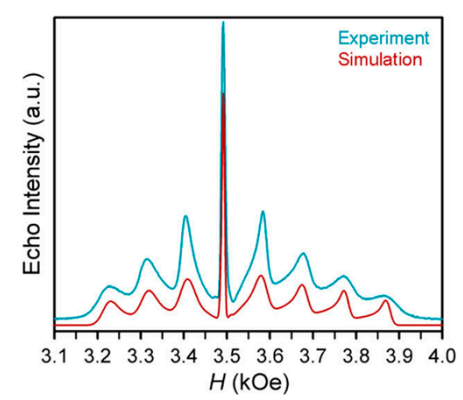

d

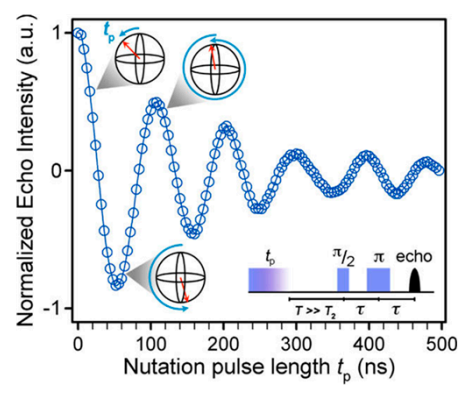

Figure 1. (a) Molecular structure of $\left[\mathrm{V}\left(\mathrm{C}_{8} \mathrm{~S}_{8}\right)_{3}\right]^{2-}$ in $\mathbf{1}$ (Green, V; yellow, S; gray, $\mathrm{C}$ ) and energies of spin states with increasing applied dc field for $\mathbf{1}$ oriented; (b) Echo-detected, field-swept, X-band spectrum of a $1 \mathrm{mM}$ solution of $\mathbf{1}$ in butyronitrile at $20 \mathrm{~K}$ (blue line); (c) Integrated echo intensity as a function of delay time $(\tau)$ for 1 under an applied dc field of 3486 Oe at $80 \mathrm{~K}$ with graphical depiction of Hahn-echo pulse sequence. Inset: Temperature dependence of $T_{2}$ for 1 ; (d) Rabi oscillations collected on a $1 \mathrm{mM}$ solution of 1 at $20 \mathrm{~K}, H_{\mathrm{dc}}=3486 \mathrm{Oe}$, and $11 \mathrm{~dB}$ attenuation of $B_{1}$ (adapted with permission from [41]). 
Subsequently, a series of $\mathrm{V}(\mathrm{IV})$ complexes $\left(\mathrm{Ph}_{4} \mathrm{P}\right)_{2}\left[\mathrm{~V}\left(\mathrm{C}_{8} \mathrm{~S}_{8}\right)_{3}\right]$ 2, $\left(\mathrm{Ph}_{4} \mathrm{P}\right)_{2}\left[\mathrm{~V}\left(\beta-\mathrm{C}_{3} \mathrm{~S}_{5}\right)_{3}\right]$ 3, $\left(\mathrm{Ph}_{4} \mathrm{P}\right)_{2}\left[\mathrm{~V}\left(\alpha-\mathrm{C}_{3} \mathrm{~S}_{5}\right)_{3}\right] 4$, and $\left(\mathrm{Ph}_{4} \mathrm{P}\right)_{2}\left[\mathrm{~V}\left(\mathrm{C}_{3} \mathrm{~S}_{4} \mathrm{O}\right)_{3}\right] 5$, based on carbonsulfides (Figure 2a-d), were prepared to test the electronic donating ability on the quantum coherence times [42]. The similar $\mathrm{S}_{6}$ coordination environment is maintained. Interestingly, the longest $T_{2}$ was found for 2 of $4 \mu \mathrm{s}$ at $80 \mathrm{~K}$, indicating the weaker donating ability is better since the donating ability sequence is $\mathrm{C}_{8} \mathrm{~S}_{8}{ }^{2-}<\beta-\mathrm{C}_{3} \mathrm{~S}_{5}{ }^{2-}<$ $\alpha-\mathrm{C}_{3} \mathrm{~S}_{5}{ }^{2-}<\mathrm{C}_{3} \mathrm{~S}_{4} \mathrm{O}^{2-}$. In addition, the solvent effect on quantum coherence was investigated. Several solvents including some deuterated ones such as $\operatorname{PrCN}, \operatorname{PrCN} / \mathrm{DMF}, \mathrm{DMF} / \mathrm{Tol}, d_{7}-\mathrm{DMF} / d_{8}-\mathrm{Tol}$ and $\mathrm{CS}_{2}$ were chosen and found they have little effect on $T_{1}$. In contrast, $T_{2}$ is significantly affected, e.g., $T_{2}$ for complex 2 in $\mathrm{CS}_{2}$ is $1.18 \mu \mathrm{s}(120 \mathrm{~K})$, which is about 10 times longer than that in $\operatorname{PrCN}$ $(0.108 \mu \mathrm{s}, 120 \mathrm{~K})$. Moreover, $\mathrm{T}_{2}$ is temperature-dependent. At $10 \mathrm{~K} \mathrm{~T}_{2}$ of 2 in $\mathrm{CS}_{2}$ solution is enhanced to $675(7) \mu \mathrm{s}$, even longer than some prominent solid-state qubits [43,44]. Remarkably, Rabi oscillations were observed for all four complexes (Figure 2e), and $Q_{M}$ for 2 was found to be 36,000, which is very high among molecule-based spin qubits. Hence, this series of V(IV) complexes indicates the spin qubits are significantly affected by nuclear spin bath.
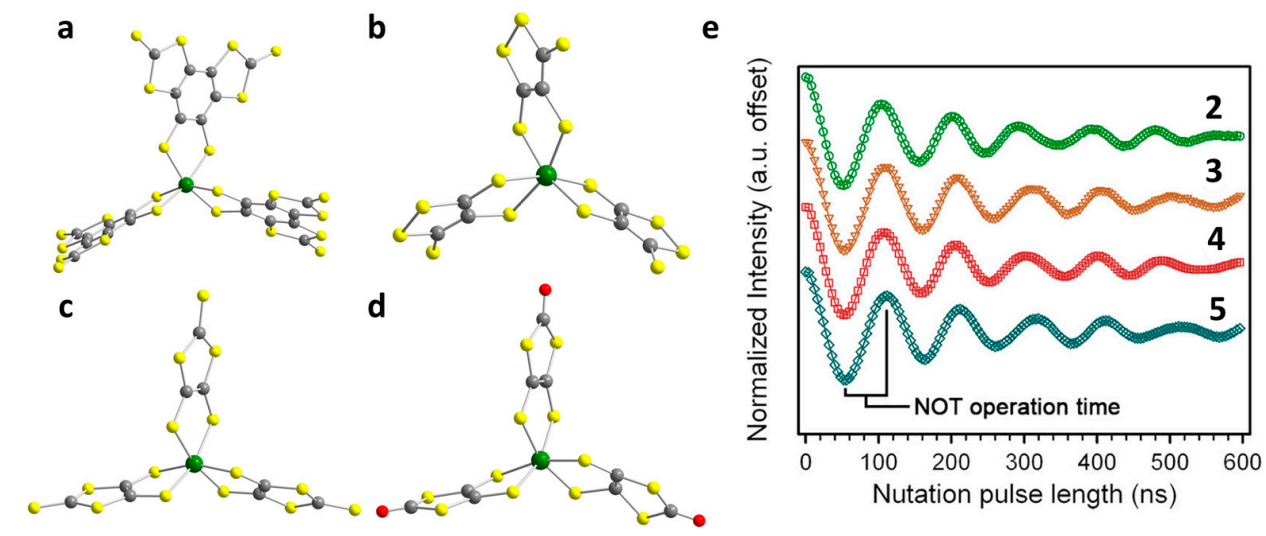

Figure 2. Molecular structures of 2-5 (a-d) (Green, V; yellow, S; gray, C; red, $\mathrm{O} ; \mathrm{Ph}_{4} \mathrm{P}$ groups are omitted for clarity); (e) Rabi oscillations for 2-5 that verify quantum control in each member of the series. Data were recorded in 1:1 DMF/Tol at $20 \mathrm{~K}$, and $14 \mathrm{~dB}$ attenuation of $B_{1}$. The spin-flip operation time of $52 \mathrm{~ns}$ is highlighted (adapted with permission from [42]).

The second class of mononuclear $\mathrm{V}(\mathrm{IV})$ based spin qubits contains the $\mathrm{VO}^{2+}$ unit with distinct short $\mathrm{V}=\mathrm{O}$ double bond (about $1.6 \AA$ ), which is much shorter than other coordination bonds bound to the central V(IV) ions in a typical square pyramidal geometry. Such strong bond is believed to be responsible for a special d-orbital splitting which leaves the $\mathrm{d}_{\mathrm{xy}}$ orbital being in the lowest place in energy levels and well separated from the other orbitals. This is evident in the complex $\mathrm{VO}(\mathrm{dpm})_{2} 6$ $\left(\mathrm{dpm}^{-}=\right.$dipivaloylmethanate) (Figure 3a) [45] whose $\mathrm{V}=\mathrm{O}$ bond length is $1.59 \AA$, while other V-O single bonds averages at $1.96 \AA$. AC magnetic susceptibility study gives out-of-phase signals up to $80 \mathrm{~K}$ for frequencies lower than $10 \mathrm{kHz}$, which is the highest one among all reported molecular magnets. The relaxation time $T_{1}$ at $80 \mathrm{~K}$ reached $13.42 \mu$ s (Figure $3 \mathrm{~d}$ ). By pulsed EPR spectroscopy, the coherence time was detected. When complex 6 was dissolved in $\mathrm{CH}_{2} \mathrm{Cl}_{2}$-toluene $(1 \mathrm{mM}), \mathrm{T}_{2}$ reaches $2.1 \mu$ s at $80 \mathrm{~K}$, and with 1:10 dispersion of diamagnetic $\mathrm{TiO}(\mathrm{dpm})_{2}$, this $T_{2}$ can be further preserved up to $220 \mathrm{~K}$. $T_{1}$ was also determined by pulsed EPR spectroscopy, which gave the consistent results for AC magnetic susceptibility study, conforming that the two techniques are actually probing the same process. Complexes $\mathrm{VO}(\mathrm{acac})_{2} 7$ and $\left.\mathrm{VO}(\mathrm{dbm})_{2} 8\right)\left(\mathrm{acac}^{-}=\right.$acetylacetonate, and $\mathrm{dbm}^{-}=$ dibenzoylmethanate) (Figure 3b,c) share a similar coordination environment to 6 [46]. The $\mathrm{V}=\mathrm{O}$ bond distances are $1.585 \AA$ and $1.578 \AA$ for 7 and 8, respectively. Both of 7 and 8 show out-of-phase AC signals under a static magnetic field of $0.2 \mathrm{~T}$ up to $40 \mathrm{~K}$, which is associated with a giant spin-phonon bottleneck effect. Moreover, a pronounced crystal size dependence of the relaxation time was observed in complexes 6-8. 

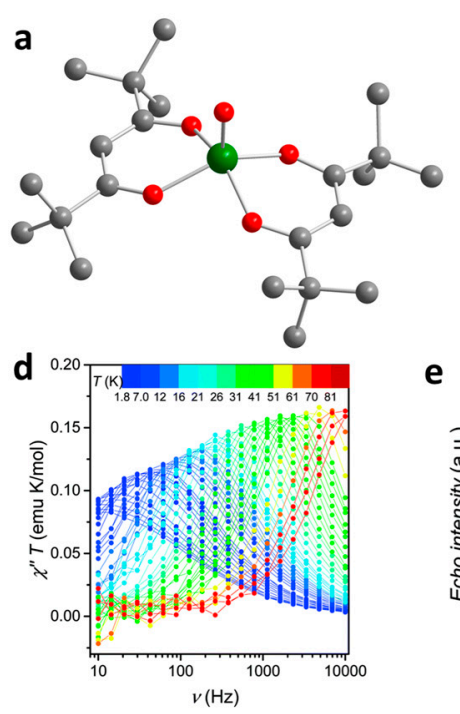

e b
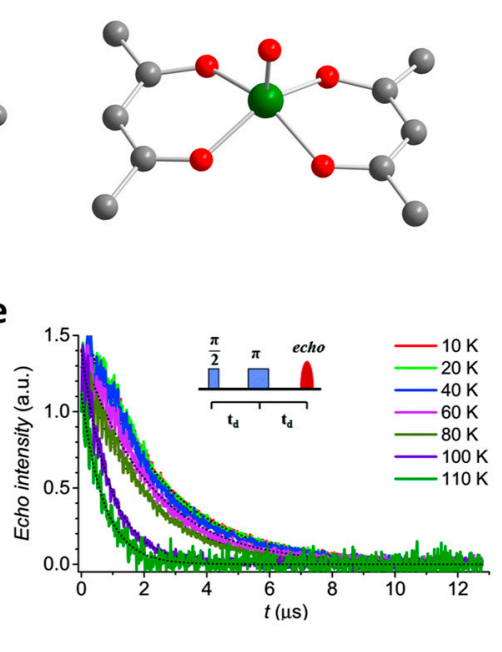

c

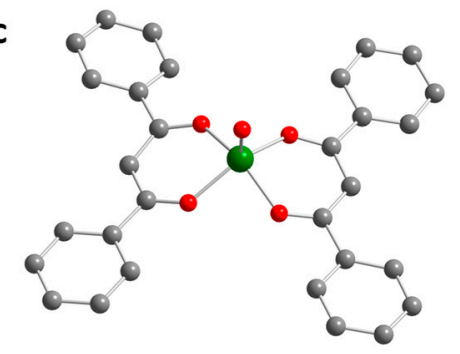

f

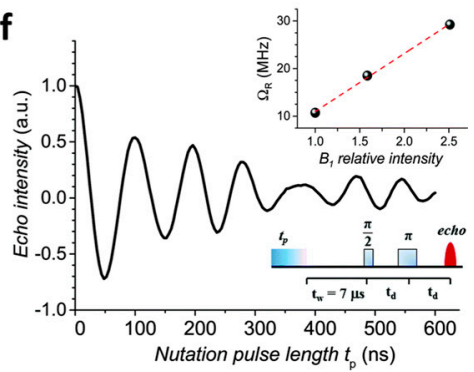

Figure 3. $(\mathrm{a}-\mathrm{c})$ Molecular structures of 6-8 (Green, V; gray, C; red, O; hydrogen atoms are omitted for clarity); (d) Frequency dependence of the imaginary component of the AC susceptibility of bulk 6 in $B_{\mathrm{dc}}=0.2 \mathrm{~T}$ multiplied by temperature to be readable in the whole $2-80 \mathrm{~K}$ temperature range; (e) Pulsed EPR Hahn echo decay traces for a frozen $1 \mathrm{mM} \mathrm{CH} \mathrm{Cl}_{2}$-toluene solution of 6 at indicated temperatures recorded at $343 \mathrm{mT}$. In the Inset the employed pulse sequence; (f) Rabi oscillations for a frozen $1 \mathrm{mM} \mathrm{CH} \mathrm{Cl}_{2}$-toluene solution of 6 recorded at $4.3 \mathrm{~K}$ at $10 \mathrm{~dB}$ microwave attenuation (adapted with permission from [45]).

Table 1. V(IV) based single-ion spin qubits.

\begin{tabular}{cccccc}
\hline Complex & $\boldsymbol{T}_{\mathbf{1}} / \boldsymbol{\mu s}$ & $\boldsymbol{T}_{\mathbf{2}} / \boldsymbol{\mu s}^{\mathbf{a}}$ & $\boldsymbol{T}_{\mathbf{2}} / \boldsymbol{\mu} \mathbf{s}^{\mathbf{b}}$ & $\boldsymbol{T}_{\mathbf{R}} / \mathbf{K}^{\mathbf{c}}$ & Ref. \\
\hline$\left(\mathrm{Bu}_{4} \mathrm{~N}\right)_{2}\left[\mathrm{~V}\left(\mathrm{C}_{8} \mathrm{~S}_{8}\right)_{3}\right](\mathbf{1})$ & - & $1.2(80 \mathrm{~K})$ & $1.52(20 \mathrm{~K})$ & 20 & {$[41]$} \\
$\left(\mathrm{Ph}_{4} \mathrm{P}\right)_{2}\left[\mathrm{~V}\left(\mathrm{C}_{8} \mathrm{~S}_{8}\right)_{3}\right](\mathbf{2})$ & $4.90(120 \mathrm{~K})$ & $1.18(120 \mathrm{~K})$ & $675(7)(10 \mathrm{~K})$ & 20 & {$[42]$} \\
$\left.\left(\mathrm{Ph}_{4} \mathrm{P}\right)_{2} \mathrm{~V}\left(\beta-\mathrm{C}_{3} \mathrm{~S}_{5}\right)_{3}\right](\mathbf{3})$ & $2.24(120 \mathrm{~K})$ & $0.86(120 \mathrm{~K})$ & $6.13(10 \mathrm{~K})$ & 20 & {$[42]$} \\
$\left(\mathrm{Ph}_{4} \mathrm{P}\right)_{2}\left[\mathrm{~V}\left(\alpha-\mathrm{C}_{3} \mathrm{~S}_{5}\right)_{3}\right](\mathbf{4})$ & $0.71(150 \mathrm{~K})$ & $0.19(150 \mathrm{~K})$ & $6.01(10 \mathrm{~K})$ & 60 & {$[42,47]$} \\
$\left(\mathrm{Ph}_{4} \mathrm{P}\right)_{2}\left[\mathrm{~V}\left(\mathrm{C}_{3} \mathrm{~S}_{4} \mathrm{O}\right)_{3}\right](\mathbf{5})$ & $3.16(120 \mathrm{~K})$ & $0.96(120 \mathrm{~K})$ & $2.79(10 \mathrm{~K})$ & 20 & {$[42]$} \\
$\mathrm{VO}(\mathrm{dpm})_{2}(\mathbf{6})$ & $6(110 \mathrm{~K})$ & $0.1(220 \mathrm{~K})$ & $2.5(10 \mathrm{~K})$ & 4.3 & {$[45]$} \\
$\mathrm{VO}(\mathrm{acac})_{2}(\mathbf{7})$ & $\approx 10^{2}(40 \mathrm{~K})$ & - & - & - & {$[46]$} \\
$\mathrm{VO}(\mathrm{dbm})_{2}(\mathbf{8})$ & $\approx 10^{2}(40 \mathrm{~K})$ & - & - & - & {$[46]$} \\
$\operatorname{VOPc}(\mathbf{9})$ & $2.4 \times 10^{6}(7 \mathrm{~K})$ & $22(10 \mathrm{~K})$ & - & - & {$[31]$} \\
$\operatorname{VOPc}(\mathbf{9})$ & $1.1(300 \mathrm{~K})$ & $0.83(300 \mathrm{~K})$ & - & 300 & {$[48]$} \\
{$\left[(\mathrm{Ph})_{4} \mathrm{P}\right]_{2}\left[\mathrm{VO}\left(\alpha-\mathrm{C}_{3} \mathrm{~S}_{5}\right)_{2}\right](\mathbf{1 0})$} & $3.37(293 \mathrm{~K})$ & $1.04(293 \mathrm{~K})$ & - & 293 & {$[47]$} \\
\hline
\end{tabular}

${ }^{\mathrm{a}}$ Reported $T_{2}$ values at the highest temperatures; ${ }^{\mathrm{b}}$ Best $T_{2}$ values; ${ }^{\mathrm{c}}$ Reported temperatures for Rabi oscillations.

Another mononuclear V(IV) based spin qubit with short $\mathrm{V}=\mathrm{O}$ bond (1.58 $\AA$ ) is the complex VOPc 9 (Pc = Phthalocyanine) (Figure 4a) [31,48]. Together with its $\mathrm{d}^{1}$ electron configuration, this molecule makes a perfect two level system for spin qubit. Moreover, the out-of-phase signals of AC magnetic susceptibility for the frequency of $10 \mathrm{kHz}$ can be observed up to $40 \mathrm{~K}$ under an applied static magnetic field of $0.2 \mathrm{~T}$. An extraordinarily long $T_{1}(2.4 \mathrm{~s}$ at $7 \mathrm{~K})$ was obtained by Q-band EPR measurements in $0.5 \mathrm{mM} \mathrm{D}_{2} \mathrm{SO}_{4}$-solution, and $\mathrm{T}_{2}$ is $20 \mu$ s at $20 \mathrm{~K}$ under the same condition [31]. When VOPc is mixed with the isostructural diamagnetic host TiOPc in molar ratio of 1:1000, quantum coherence could be detected up to room temperature. $T_{1}$ of $1.1 \mu \mathrm{s}$ at $300 \mathrm{~K}$ was obtained by inversion recovery experiments and by echo decay experiments, echo decay traces (Figure $4 \mathrm{~b}$ ) were detected up to room temperature with $T_{2}$ of $0.83 \mu \mathrm{s}$. Hence, for the first time, Rabi oscillation at room temperatures was detected in a solid state molecular system (Figure 4c). Besides, the quantum states of this electron spins based system can be efficiently initialized with high thermal stability, representing a promising qubit. 
a

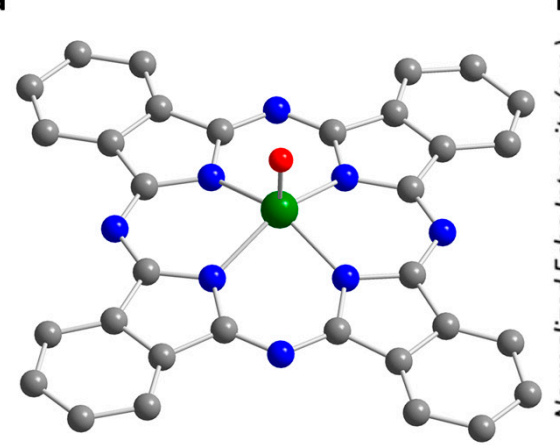

b

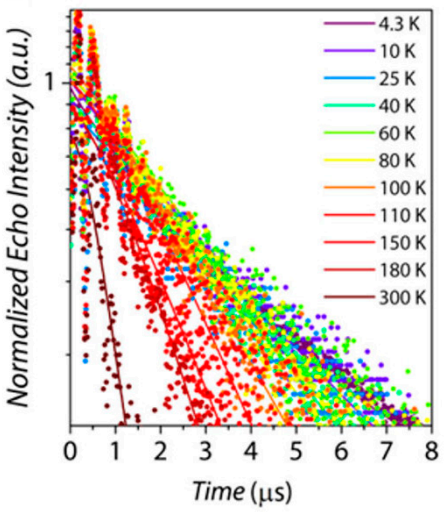

c

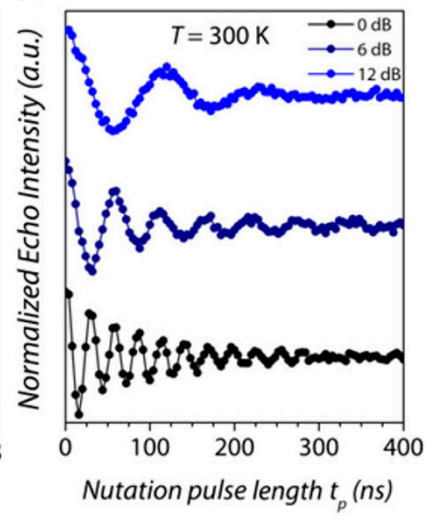

Figure 4. (a) Molecular structures of 9 (Green, V; gray, C; red, O; blue, N; hydrogen atoms are omitted for clarity); (b) Echo decay traces for 9 at indicated temperatures performed at $345 \mathrm{mT}$. Solid lines are the best fits; (c) Rabi oscillations recorded for 9 at $300 \mathrm{~K}$ for different microwave attenuations performed at $345 \mathrm{mT}$ (adapted with permission from [48]).

More recently, a new mononuclear V(IV) complex $\left(\mathrm{Ph}_{4} \mathrm{P}\right)_{2}\left[\mathrm{VO}\left(\alpha-\mathrm{C}_{3} \mathrm{~S}_{5}\right)_{2}\right] 10$ was reported, which enhances the quantum coherence by strong $\mathrm{V}=\mathrm{O}$ double bond [47]. As shown in Figure 5a, the structure of $\mathbf{1 0}$ is similar to $\mathbf{4}$ except for the apical $\mathrm{O}$ atom. For comparison, the dynamic magnetism of both complexes was studied. Under a static magnetic field of $0.2 \mathrm{~T}$, complex 4 displays slow magnetic relaxations below $10 \mathrm{~K}$; while for complex 10, the temperature is raised up to $40 \mathrm{~K}$. Their quantum coherences were detected by continuous-wave and pulsed EPR measurements on diluted samples. For 4, it was dispersed by $\left[(\mathrm{Ph})_{4} \mathrm{P}\right]_{2}\left[\mathrm{Ti}\left(\alpha-\mathrm{C}_{3} \mathrm{~S}_{5}\right)_{3}\right]$ in a molar ratio of $1: 19$, which gives $T_{1}$ of $0.71 \mu \mathrm{s}$ and $T_{2}$ of $0.19 \mu$ s at $150 \mathrm{~K}$ (Figure $5 \mathrm{c}$ ). Complex 10 was mixed with $\left[(\mathrm{Ph})_{4} \mathrm{P}\right]_{2}\left[\mathrm{MoO}\left(\alpha-\mathrm{C}_{3} \mathrm{~S}_{5}\right)_{2}\right]$ in a molar ratio of 1:19 for pulsed EPR measurements. At room temperature (293 K), both $T_{1}$ and $T_{2}$ of $\mathbf{1 0}$ remain high, namely $3.37 \mu$ s and $1.04 \mu$ s (Figure $5 b$ ). Rabi oscillations are also clearly observed at $293 \mathrm{~K}$ for diluted 10 and at $60 \mathrm{~K}$ for diluted 4, indicating the enhancement of $\mathrm{O}$ substitution.
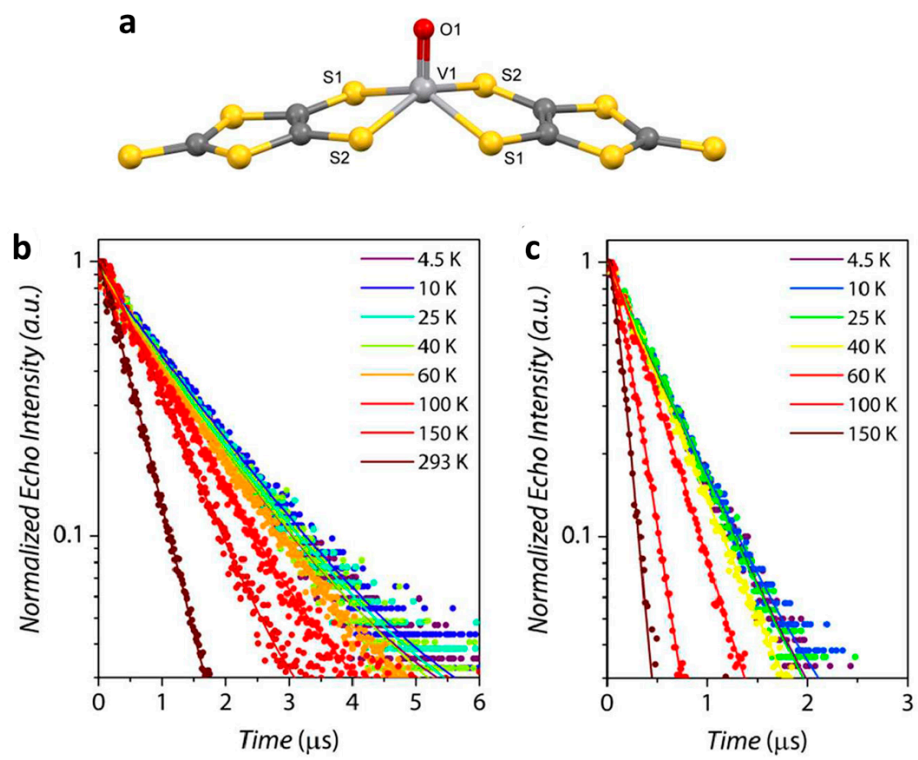

Figure 5. (a) Molecular structure of $\mathbf{1 0}$ (Green, V; yellow, $\mathrm{S}$; gray, $\mathrm{C} ; \mathrm{Ph}_{4} \mathrm{P}$ groups are omitted for clarity); (b) Echo decay traces for diluted $\mathbf{1 0}$ at indicated temperatures performed at X-band; (c) Echo decay traces for diluted 4 at indicated temperatures performed at X-band. Solid lines are the best fits (adapted with permission from [47]). 


\subsection{Cu(II) Based Single-Ion Spin Qubits}

Except for V(IV), $\mathrm{Cu}(\mathrm{II})$ is another ion with spin-1/2 state. Several examples of mononuclear $\mathrm{Cu}$ (II) complexes have been reported as potential single-ion spin qubits (Table 2). The first one is CuPc 11 (Figure 6a) [31,49]. By organic-molecular-beam deposition, complex $\mathbf{1 1}$ and free phthalocyanine are able to assemble a monoatomic layer onto the layer of perylene-3,4,9,20-tetracarboxylic dianhydride. With the Hahn echo sequence, $T_{2}$ for $\mathbf{1 1}$ was determined to be $1 \mu$ s at $80 \mathrm{~K}$. Moreover, Rabi oscillations of a $0.1 \%$ CuPc: $\mathrm{H}_{2}$ Pc were clearly observed at $5 \mathrm{~K}$ (Figure 6c) [49]. The impact of solvent deuteration on electron spin relaxation has been investigated by dissolving 11 in $\mathrm{H}_{2} \mathrm{SO}_{4}$ and $\mathrm{D}_{2} \mathrm{SO}_{4}$ [31]. For $\mathrm{D}_{2} \mathrm{SO}_{4}$, $T_{2}$ is about $41 \mu \mathrm{s}$ at $7 \mathrm{~K}$, which is five times longer than those in $\mathrm{H}_{2} \mathrm{SO}_{4}$ (Figure $6 \mathrm{~b}$ ). The ligand effect on the quantum coherence times was also investigated using complexes $\mathrm{CuPc}^{\mathrm{Cl}} \mathbf{1 2}$ and $\mathrm{CuPc}^{\mathrm{F}} 13$. All the three complexes share a similar $T_{2}$ value of $40 \mu \mathrm{s}$ at $7 \mathrm{~K}$, indicating the ligand field effect is little in this series [31].

Table 2. $\mathrm{Cu}(\mathrm{II})$ based single-ion spin qubits.

\begin{tabular}{cccccc}
\hline Complex & $T_{\mathbf{1}} / \boldsymbol{\mu s}$ & $\boldsymbol{T}_{\mathbf{2}} / \mathbf{\mu s}^{\mathbf{a}}$ & $\boldsymbol{T}_{\mathbf{2}} / \boldsymbol{\mu \mathbf { s }} \mathbf{b}^{\mathbf{b}}$ & $\boldsymbol{T}_{\mathbf{R}} / \mathbf{K}^{\mathbf{c}}$ & Ref. \\
\hline $\mathrm{CuPc}(\mathbf{1 1})$ & $10^{5}(7 \mathrm{~K})$ & $1.0(80 \mathrm{~K})$ & $41(7 \mathrm{~K})$ & 5 & {$[31,49]$} \\
$\mathrm{CuPcCl}(\mathbf{1 2})$ & $10^{5}(7 \mathrm{~K})$ & $40(7 \mathrm{~K})$ & - & - & {$[31]$} \\
$\mathrm{CuPcF}(\mathbf{1 3})$ & $6 \times 10^{4}(7 \mathrm{~K})$ & $40(7 \mathrm{~K})$ & - & - & {$[31]$} \\
$\left(\mathrm{PPh}_{4}\right)_{2}\left[\mathrm{Cu}(\mathrm{mnt})_{2}\right](\mathbf{1 4})$ & $0.48(294 \mathrm{~K})$ & $0.6(294 \mathrm{~K})$ & $68(7 \mathrm{~K})$ & 15 & {$[50]$} \\
\hline
\end{tabular}

${ }^{\mathrm{a}}$ Reported $T_{2}$ values at the highest temperatures; ${ }^{\mathrm{b}}$ Best $T_{2}$ values; ${ }^{\mathrm{c}}$ Reported temperatures for Rabi oscillations.

a

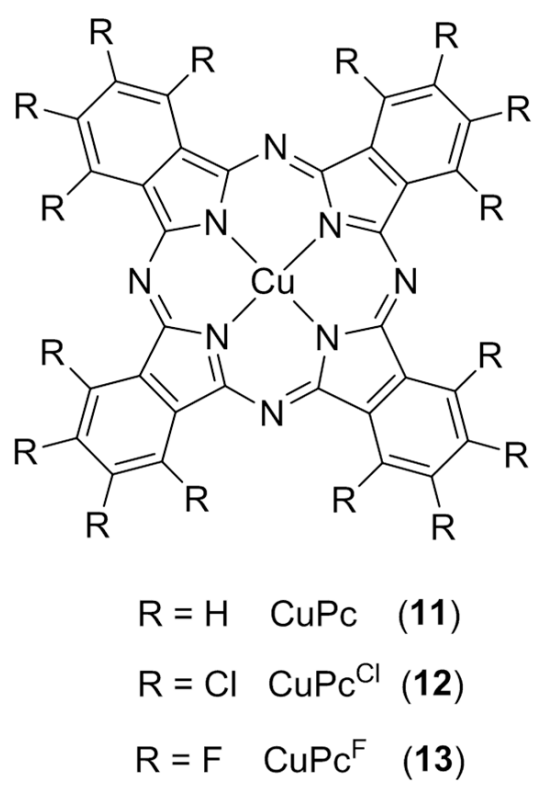

b
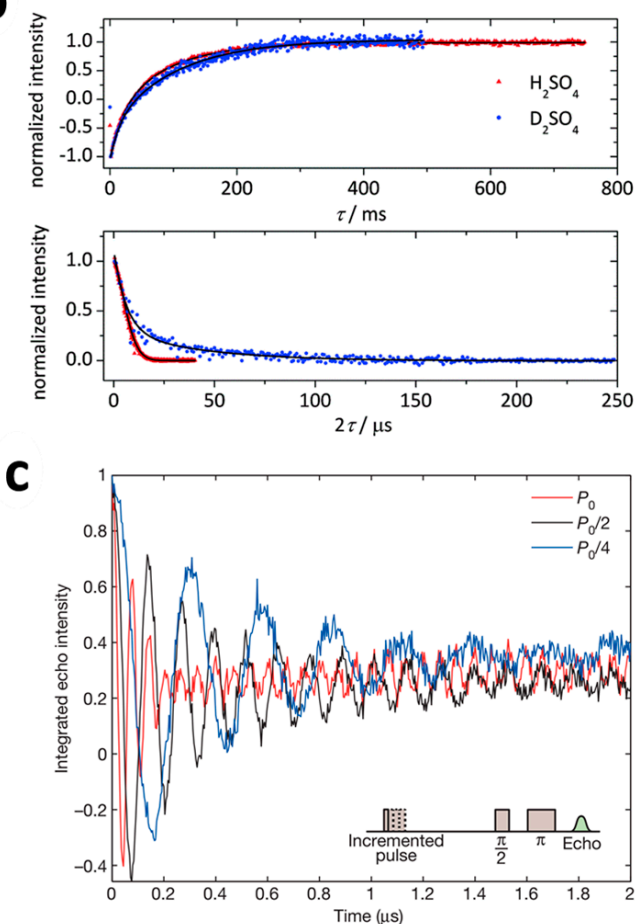

Figure 6. (a) Structures of complexes 11-13; (b) Inversion recovery experiment (up) and Hahn echo experiment (down) for relaxation data of $\mathbf{1 1}$ in $\mathrm{H}_{2} \mathrm{SO}_{4}$ (red triangles) and $\mathrm{D}_{2} \mathrm{SO}_{4}$ (blue circles) at Q-band and $7 \mathrm{~K}$ (adapted with permission from [31]); (c) Rabi oscillations of a $0.1 \% \mathrm{CuPc}: \mathrm{H}_{2} \mathrm{Pc}$ film recorded at $5 \mathrm{~K}$ and $330.5 \mathrm{mT}$ for different microwave powers (adapted with permission from [49]).

$\left(\mathrm{PPh}_{4}\right)_{2}\left[\mathrm{Cu}(\mathrm{mnt})_{2}\right] 14\left(\mathrm{mnt}^{2-}=\right.$ maleonitriledithiolate or 1,2-dicyanoethylene-1,2-dithiolate $)$ is another high-performance single-ion spin qubit that displays long quantum coherence times at room temperature [50]. The $\mathrm{Cu}(\mathrm{II})$ ion in $\mathbf{1 4}$ is coordinated to four $\mathrm{S}$ ions in a square planner geometry 
(Figure 7a). The $\mathrm{H}$ atoms in this complex can be fully replaced by deuterium and its Ni analogy is diamagnetic, allowing a magnetic dilution study. At $294 \mathrm{~K}$, electron spin echo-detected EPR measurements of the highly diluted sample $\left(0.0001 \%\right.$ of 14 in $\left.\left(\mathrm{PPh}_{4}\right)_{2}\left[\mathrm{Ni}(\mathrm{mnt})_{2}\right]\right)$ gave $T_{1}$ of $0.48 \mu \mathrm{s}$ and $T_{2}$ of $0.6 \mu$ s (Figure $7 \mathrm{~b}$ ). Towards lower temperatures with $0.01 \%$ deuterated 14 in deuterated $\left(\mathrm{PPh}_{4}\right)_{2}\left[\mathrm{Ni}(\mathrm{mnt})_{2}\right], T_{2}$ is prolonged to $68 \mu$ s at $7 \mathrm{~K}$. Moreover, Rabi-like oscillations of the echo intensities were clearly observed by nutation measurements of the same sample at $15 \mathrm{~K}$ with a merit $Q_{M} \approx 3400$.

a

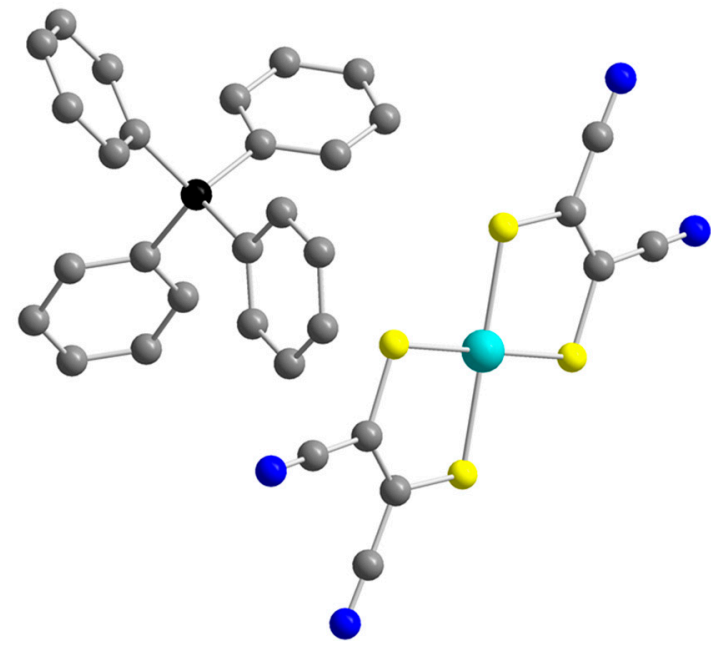

b

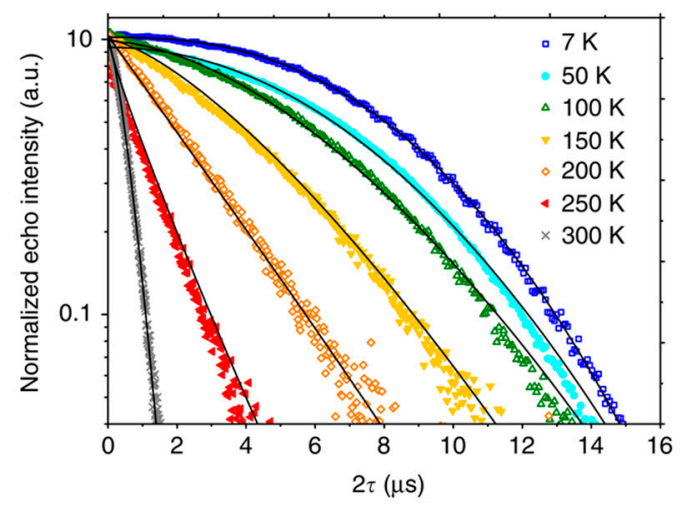

Figure 7. (a) Molecular structure of $\mathbf{1 4}$ (Aqua, Cu; yellow, S; blue, N; black, P; gray, C; hydrogen atoms

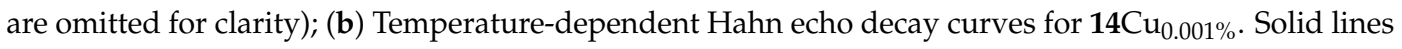
are the best fits (adapted with permission from [50]).

\subsection{Other Transition Metals}

Only two Cr(III) (spin-3/2) based single-spin qubits have been reported so far (Table 3). The first one is $\left(\mathrm{Ph}_{4} \mathrm{P}\right)_{3}\left[\mathrm{Cr}\left(\mathrm{C}_{3} \mathrm{~S}_{5}\right)_{3}\right] 15$, in which the $\mathrm{Cr}(\mathrm{III})$ ion is coordinated to six $\mathrm{S}$ atoms with a first-circle nuclear spin free coordination environment (Figure 8a) [51]. By magnetometer and continuous-wave EPR spectroscopy, $D=+0.326(8) \mathrm{cm}^{-1}$ and $E=-0.107(5) \mathrm{cm}^{-1}$ were determined, which gave a rhombicity $|E / D|$ of 0.31 . The high rhombicity would afford highly mixed $M_{S}$ levels at low magnetic fields, producing significant intensity of forbidden EPR transitions with multiple $M_{S}$ pairs for quantum studies. Pulsed X-band EPR spectroscopy measurement was carried out on deuterated 15 in $\left(d^{20}-\mathrm{Ph}_{4} \mathrm{P}\right)_{3}\left[\mathrm{Ga}\left(\mathrm{C}_{3} \mathrm{~S}_{5}\right)_{3}\right](1 \%)$ (Figure 8b). $T_{1}$ sharply drops from $29(3) \mathrm{ms}$ at $5 \mathrm{~K}$ to $875(5) \mu \mathrm{s}$ at $30 \mathrm{~K}$, while $T_{2}$ drops from $1.81(3) \mu \mathrm{s}$ to $0.82(2) \mu$ s upon the same temperature change. Moreover, Rabi oscillations were clearly observed at $5 \mathrm{~K}$ with linear $\Omega_{\mathrm{R}}$ against $B_{1}$, indicating the provenance of the nutations (Figure $8 \mathrm{c}, \mathrm{d}$ ).

The other $\mathrm{Cr}(\mathrm{III})$ based single-ion spin qubit is $\mathrm{K}_{3}\left[\mathrm{Cr}\left(\mathrm{C}_{2} \mathrm{O}_{4}\right)_{3}\right] \mathbf{1 6}$ (Figure 9a) [33]. The ID | value of 16 is about $0.7 \mathrm{~cm}^{-1}$ and the $E$ value is about $0.06 \mathrm{~cm}^{-1}$ [52]. The inherent scalability and tunability engendered by zero-field splitting are illustrated in Figure $9 \mathrm{~b}$. The transitions between the multiple $M_{\mathrm{S}}$ pairs can be used as qubits, which is in accordance with the study of complex $\mathbf{1 5}$ [51]. $T_{2}$ for $\mathbf{1 6}$ is about $1.27 \mu \mathrm{s}$ at $22 \mathrm{~K}$, obtained by two-pulse Hahn echo sequence on $1 \mathrm{mM}$ solutions of 16 in 1:1 $(v / v)$ $\mathrm{H}_{2} \mathrm{O} /$ glycerol (Figure 9c) [33]. 
a

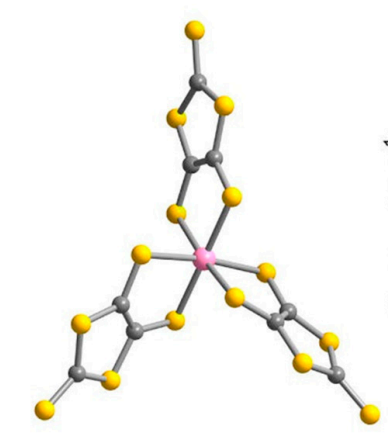

b
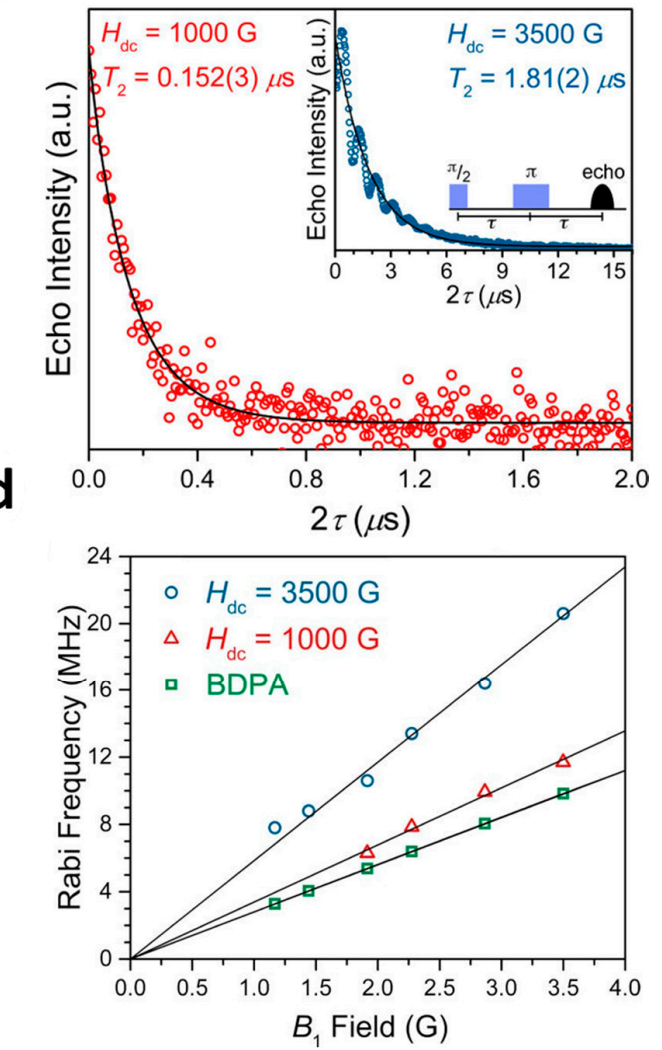

Figure 8. (a) Molecular structure of $\left[\mathrm{Cr}\left(\mathrm{C}_{3} \mathrm{~S}_{5}\right)_{3}\right]^{3-}$ in 15 (Pink, $\mathrm{Cr}$; yellow, $\mathrm{S}$; gray, $\mathrm{C}, \mathrm{Ph}_{4} \mathrm{P}$ groups are omitted for clarity) and calculated splitting of the $M_{\mathrm{S}}$ energy levels with $H_{\mathrm{dc}}=2000 \mathrm{G}$ aligned along the $\mathrm{z}$-axis of the molecule (arrows illustrate the allowed (green) and forbidden (purple) transitions within the $s=3 / 2$ manifold); (b) Hahn-echo decay curves for $1 \%$ of deuterated 15 in $\left(d^{20}-\mathrm{Ph}_{4} \mathrm{P}\right)_{3}\left[\mathrm{Ga}\left(\mathrm{C}_{3} \mathrm{~S}_{5}\right)_{3}\right]$ at $5 \mathrm{~K}$. Lines are best fits; (c) Rabi oscillations at $H_{\mathrm{dc}}=3500$ and $1000 \mathrm{G}$ and Rabi frequency dependence on $B_{1}$; (d) Rabi frequency plotted as a function of increasing $B_{1}$ for $1 \%$ of deuterated 15 in $\left(d^{20}-\mathrm{Ph}_{4} \mathrm{P}\right)_{3}\left[\mathrm{Ga}\left(\mathrm{C}_{3} \mathrm{~S}_{5}\right)_{3}\right]$ and BDPA (1,3-bisdiphenylene-2-phenylallyl radical) at $5 \mathrm{~K}$ (adapted with permission from [51]).

a

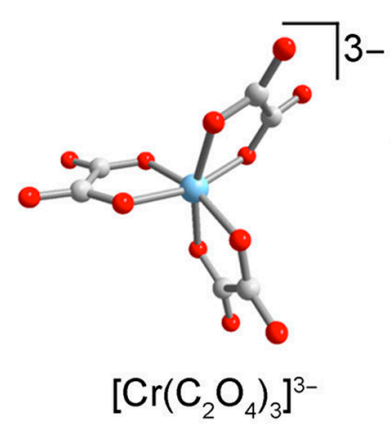

b

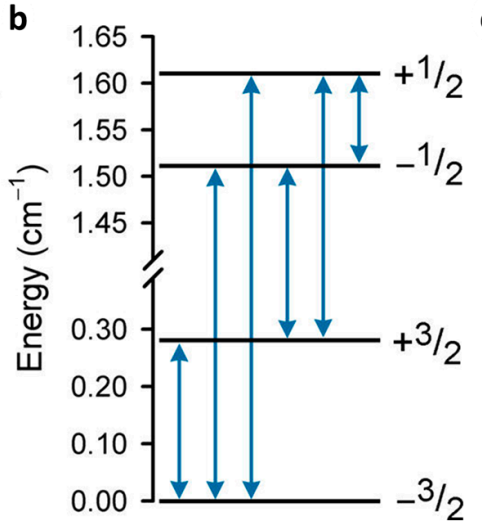

C

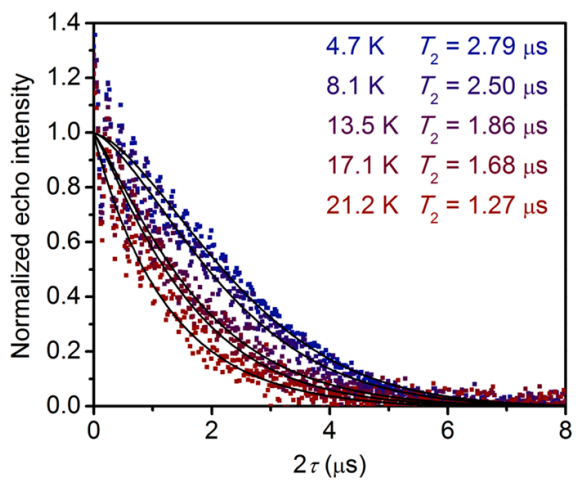

Figure 9. (a) Molecular structure of $\left[\mathrm{Cr}\left(\mathrm{C}_{2} \mathrm{O}_{4}\right)_{3}\right]^{3-}$ in 16 (Light blue, $\mathrm{Cr}$; red, O; gray, $\mathrm{C}$; cations are omitted for clarity); (b) Calculated splitting of the $M_{\mathrm{S}}$ energy levels with $H_{\mathrm{dc}}=1000 \mathrm{G}$ aligned along the $\mathrm{z}$-axis of the molecule. Blue arrows indicate the six potential qubits; (c) $T_{2}$ decay curves for $\mathbf{1 6}$ at indicated temperatures. Lines are best fits (adapted with permission from [33]). 
A series of analogous complexes $\mathrm{K}_{3}\left[\mathrm{Fe}\left(\mathrm{C}_{2} \mathrm{O}_{4}\right)_{3}\right] 17,\left(\mathrm{Ph}_{4} \mathrm{P}\right)_{3}\left[\mathrm{Fe}(\mathrm{CN})_{6}\right] 18, \mathrm{~K}_{3}\left[\mathrm{Ru}\left(\mathrm{C}_{2} \mathrm{O}_{4}\right)_{3}\right] 19$, $\left(\mathrm{Ph}_{4} \mathrm{P}\right)_{3}\left[\mathrm{Ru}(\mathrm{CN})_{6}\right] 20,\left(\mathrm{Ph}_{4} \mathrm{P}\right)_{3}\left[\mathrm{Os}(\mathrm{CN})_{6}\right] 21$ and 16 were used to study the influence of spin-spin and spin-orbit couplings on quantum coherence [33]. Complexes 19, 16 and 17 possess spin states of $s=1 / 2,3 / 2$, and $5 / 2$ with the same coordination environment, which gives an opportunity to understand the impact of spin magnitude on quantum coherence (Figure 10a). At low temperature, $T_{2}$ value for 19 is the longest one ( $3.44 \mu$ s at $5 \mathrm{~K}$ and $2.01 \mu$ s at $14 \mathrm{~K})$, followed by 16 ( $2.79 \mu$ s at $5 \mathrm{~K}$ and 1.86 $\mu$ s at $14 \mathrm{~K})$ and then $17(1.83 \mu$ s at $5 \mathrm{~K}$ and $0.81 \mu$ s at $14 \mathrm{~K})$. This result indicates a larger spin increases the intermolecular dipolar interaction and hence enhances the decoherence rate [53-55]. However, at a higher temperature ( $22 \mathrm{~K}), T_{2}$ for 16 becomes the longest, reaching $1.27 \mu \mathrm{s}$, which may also indicate spin magnitude can be varied without significantly compromising $T_{2}$ in certain conditions as long as it is appropriate for signal detection. As the spin states for complexes 18, 20, 21 are all 1/2, and the free ion SOC effects on $T_{2}$ can be compared. $T_{2}$ for those three complexes are in the order $\mathrm{Fe}(\mathrm{III})<\mathrm{Ru}(\mathrm{III})$ $<\mathrm{Os}(\mathrm{III})$, which is coincident with the increase of SOC constants, namely $464 \mathrm{~cm}^{-1}, 880 \mathrm{~cm}^{-1}$, and $3100 \mathrm{~cm}^{-1}$ for 18, 20 and 21 (Figure 10a and Table 3) [56-58]. Rabi oscillations and pulse sequence for a solution of 19 at $5 \mathrm{~K}, H_{\mathrm{dc}}=2812 \mathrm{G}$, and relative $B_{1}$ of 2.0 was observed (Figure 10b). Note that 21 is the only Os complex regarded as potential qubit.

Table 3. Other transition metals based single-ion spin qubits.

\begin{tabular}{cccccc}
\hline Complex & $\boldsymbol{T}_{\mathbf{1}} / \boldsymbol{\mu s}$ & $\boldsymbol{T}_{\mathbf{2}} / \boldsymbol{\mu} \mathbf{s}^{\mathbf{a}}$ & $\boldsymbol{T}_{\mathbf{2}} / \boldsymbol{\mu} \mathbf{s}^{\mathbf{b}}$ & $\boldsymbol{T}_{\mathbf{R}} / \mathbf{K}^{\mathbf{c}}$ & Ref. \\
\hline$\left(\mathrm{Ph}_{4} \mathrm{P}\right)_{3}\left[\mathrm{Cr}\left(\mathrm{C}_{3} \mathrm{~S}_{5}\right)_{3}\right](\mathbf{1 5})$ & $875(30 \mathrm{~K})$ & $0.82(30 \mathrm{~K})$ & $1.81(5 \mathrm{~K})$ & $5 \mathrm{~K}$ & {$[51]$} \\
$\mathrm{K}_{3}\left[\mathrm{Cr}\left(\mathrm{C}_{2} \mathrm{O}_{4}\right)_{3}\right](\mathbf{1 6})$ & - & $1.27(22 \mathrm{~K})$ & $2.79(5 \mathrm{~K})$ & - & {$[33]$} \\
$\mathrm{K}_{3}\left[\mathrm{Fe}\left(\mathrm{C}_{2} \mathrm{O}_{4}\right)_{3}\right](\mathbf{1 7})$ & - & $0.45(22 \mathrm{~K})$ & $1.83(5 \mathrm{~K})$ & - & {$[33]$} \\
$\left(\mathrm{Ph}_{4} \mathrm{P}\right)_{3}\left[\mathrm{Fe}(\mathrm{CN})_{6}\right](\mathbf{1 8})$ & - & $0.60(22 \mathrm{~K})$ & $2.38(5 \mathrm{~K})$ & - & {$[33]$} \\
$\mathrm{K}_{3}\left[\mathrm{Ru}\left(\mathrm{C}_{2} \mathrm{O}_{4}\right)_{3}\right](\mathbf{1 9})$ & - & $0.41(22 \mathrm{~K})$ & $3.44(5 \mathrm{~K})$ & 5 & {$[33]$} \\
$\left(\mathrm{Ph}_{4} \mathrm{P}\right)_{3}\left[\mathrm{Ru}(\mathrm{CN})_{6}\right](\mathbf{2 0})$ & - & $1.29(22 \mathrm{~K})$ & $2.55(5 \mathrm{~K})$ & - & {$[33]$} \\
$\left(\mathrm{Ph}_{4} \mathrm{P}\right)_{3}\left[\mathrm{Os}(\mathrm{CN})_{6}\right](\mathbf{2 1})$ & - & $1.04(22 \mathrm{~K})$ & $4.12(5 \mathrm{~K})$ & - & {$[33]$} \\
$\left(\mathrm{Ph}_{4} \mathrm{P}\right)_{3}\left[\mathrm{Fe}\left(\mathrm{C}_{5} \mathrm{O}_{5}\right)_{3}\right](\mathbf{2 2})$ & $1.18(15 \mathrm{~K})$ & $0.498(40 \mathrm{~K})$ & $1.63(5 \mathrm{~K})$ & 10 & {$[59]$} \\
$\mathrm{MnPc}(\mathbf{2 3})$ & $690(7 \mathrm{~K})$ & $14(7 \mathrm{~K})$ & - & - & {$[31]$} \\
$\mathrm{CoPc}(\mathbf{2 4})$ & $1.11 \times 10^{4}(7 \mathrm{~K})$ & $9.44(7 \mathrm{~K})$ & - & - & {$[31]$} \\
\hline
\end{tabular}

${ }^{a}$ Reported $T_{2}$ values at the highest temperatures; ${ }^{\mathrm{b}}$ Best $T_{2}$ values; ${ }^{\mathrm{c}}$ Reported temperatures for Rabi oscillations.

a

\section{Spin series (S)}

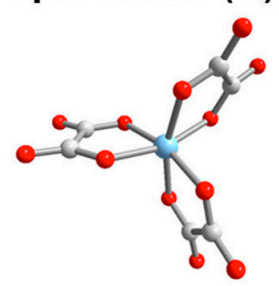

$\left[\mathrm{M}^{\prime \prime \prime}\left(\mathrm{C}_{2} \mathrm{O}_{4}\right)_{3}\right]^{3-}$

$\mathrm{M}=\mathrm{Ru}, S=1 / 2$

$\mathrm{M}=\mathrm{Cr}, S=3 / 2$

$\mathrm{M}=\mathrm{Fe}, S=5 / 2$
Spin-orbit series $(\zeta)$

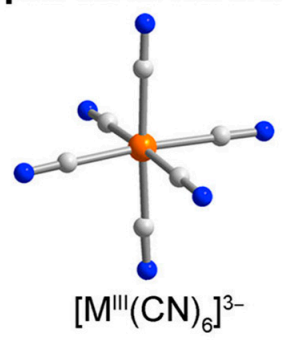

$\mathrm{M}=\mathrm{Fe}, \zeta=464 \mathrm{~cm}^{-1}$

$\mathrm{M}=\mathrm{Ru}, \zeta=880 \mathrm{~cm}^{-1}$

$M=O s, \zeta=3100 \mathrm{~cm}^{-1}$ b

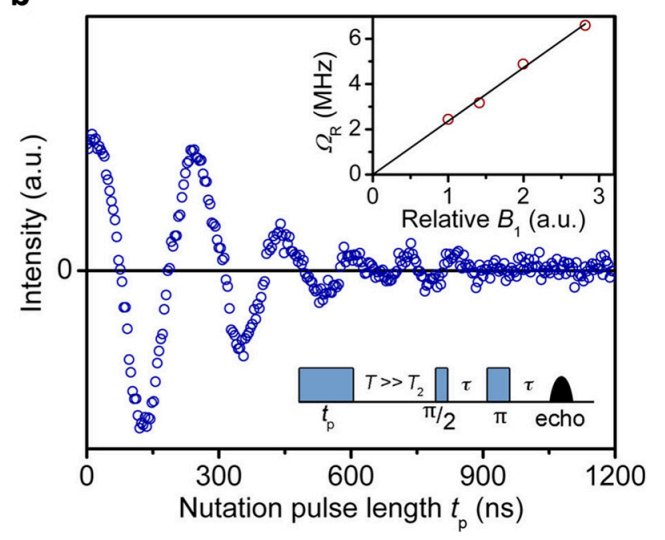

Figure 10. (a) Depictions of the molecular structures of 16, 17 and 19 (left) and 18, 20 and 21 (right) (cations are omitted for clarity); (b) Rabi oscillations and pulse sequence for a solution of 19 at $5 \mathrm{~K}$ (adapted with permission from [33]).

Another $\mathrm{Fe}(\mathrm{III})$ based single-ion spin qubit is the complex $\left(\mathrm{Ph}_{4} \mathrm{P}\right)_{3}\left[\mathrm{Fe}\left(\mathrm{C}_{5} \mathrm{O}_{5}\right)_{3}\right] 22$ (Figure 11a) $[59,60]$. Variable-frequency CW EPR measurements at low temperatures $(5 \mathrm{~K})$ and high frequencies $(208 \mathrm{GHz})$ on this trigonally distorted six-coordinate iron(III) complexes with $\mathrm{O}_{6}$ coordination environments reveal a sharp resonance near $g=2.00$ and negative $D$ value of $-0.30 \mathrm{~cm}^{-1}$. To evaluate the spin 
qubit viability of 22, its diamagnetic analogy $\left(\mathrm{Ph}_{4} \mathrm{P}\right)_{3}\left[\mathrm{Ga}\left(\mathrm{C}_{5} \mathrm{O}_{5}\right)_{3}\right]$ was used for preparations of diluted samples, $\left(\mathrm{Ph}_{4} \mathrm{P}\right)_{3}\left[\mathrm{Fe}_{0.002} \mathrm{Ga}_{0.998}\left(\mathrm{C}_{5} \mathrm{O}_{5}\right)_{3}\right]$ 22a and the deuterated $\left(\mathrm{Ph}_{4} \mathrm{P}-\mathrm{d}^{20}\right)_{3}\left[\mathrm{Fe}_{0.002} \mathrm{Ga}_{0.998}\left(\mathrm{C}_{5} \mathrm{O}_{5}\right)_{3}\right]$ $22 \mathrm{~b}$ for pulsed EPR studies. At $5 \mathrm{~K}, T_{1}$ are $11.3 \mu \mathrm{s}$ and $8.0 \mu \mathrm{s}$ for $22 \mathrm{a}$ and $22 \mathrm{~b}$, respectively. These values drop dramatically as increasing temperatures, which eventually went down to $1.18 \mu \mathrm{s}$ and $0.82(1) \mu \mathrm{s}$, respectively, at $15 \mathrm{~K} . T_{2}$ values for $22 \mathrm{a}$ and $22 \mathrm{~b}$ at $5 \mathrm{~K}$ are $0.74 \mu \mathrm{s}$ and $1.60 \mu \mathrm{s}$, respectively, highlighting the enhancement of $T_{2}$ with deuteration. Similar to $T_{1}, T_{2}$ also decay rapidly upon warming, ultimately down to $0.34 \mu$ s for 22a at $15 \mathrm{~K}$. Moreover, clear Rabi oscillations were observed for both 22a and 22b at $10 \mathrm{~K}$ (Figure 11c,d) with liner dependence of $\Omega_{\mathrm{R}}$ against $B_{1}$, proving the qubit characteristic [59]. By multi-frequency pulsed EPR spectroscopic measurements, a high to low degree of $M_{\mathrm{S}}$ mixing in the high-spin qubit was discovered in 22, which highlights the possibility of long $T_{1}$ and $T_{2}$ parameters in high-spin species through control of $M_{\mathrm{S}}$ level mixing [60].

a

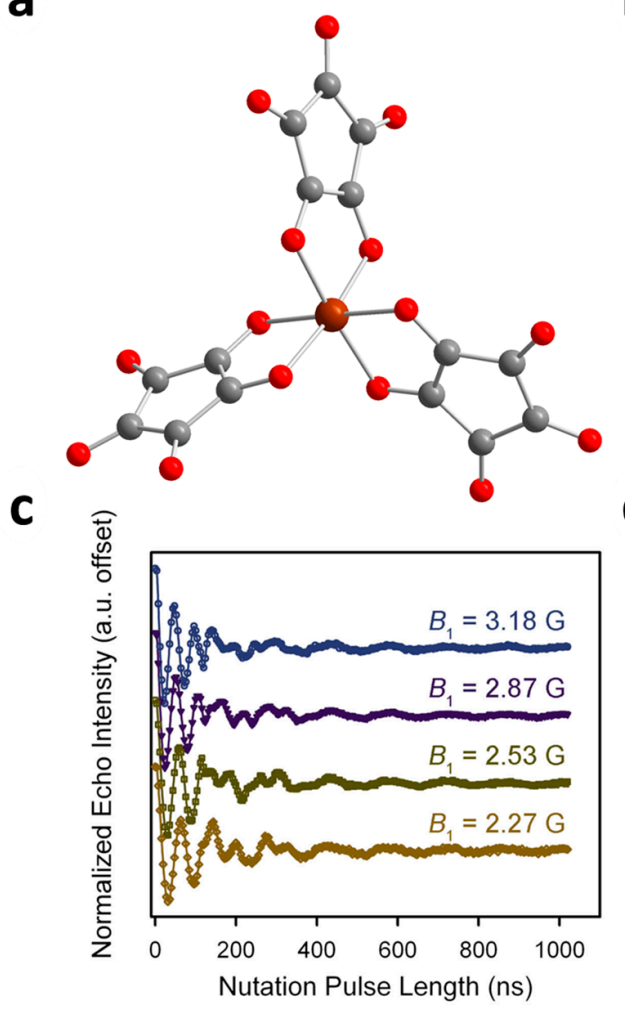

b

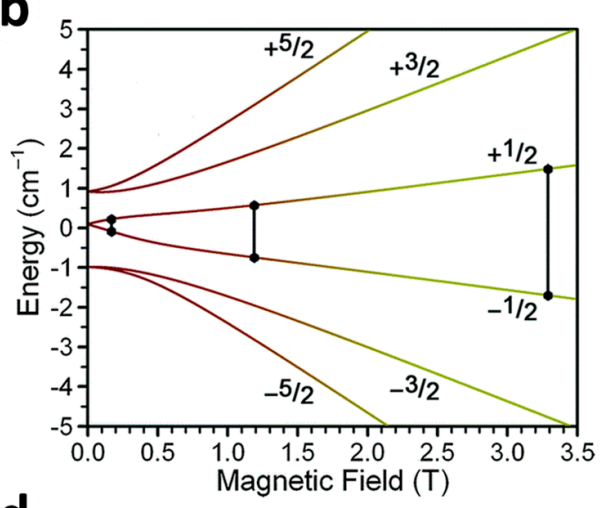

d

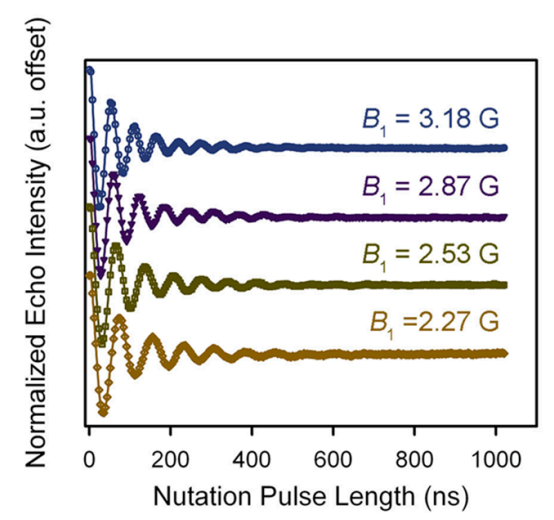

Figure 11. (a) Molecular structure of $\left[\mathrm{Fe}\left(\mathrm{C}_{5} \mathrm{O}_{5}\right)_{3}\right]^{3-}$ in 22 (Brown, Fe; red, $\mathrm{O}$; gray, $\mathrm{C}$; the $\mathrm{Ph}_{4} \mathrm{P}$ groups are omitted for clarity); (b) Magnetic field dependence of the $M_{\mathrm{S}}$ levels of the $s=5 / 2$ state in 22 for a magnetic field aligned perpendicular to the molecular $\mathrm{z}$-axis (adapted with permission from [60]); (c) Rabi oscillations at $H_{\mathrm{dc}}=1608 \mathrm{G}$ with indicated $B_{1}$ for 22a at $10 \mathrm{~K}$ (adapted with permission from [59]; (d) Rabi oscillations at $H_{\mathrm{dc}}=1608 \mathrm{G}$ with indicated $B_{1}$ for 22b at $10 \mathrm{~K}$ (adapted with permission from [60].

As far as we know, few mononuclear $\mathrm{Mn}$ and Co complexes were reported as potential spin qubits. The only investigation of these two ions was found in complexes MnPc (23) and CoPc (24), which were used to reveal the influences of central ion on quantum coherence behavior of complexes $\mathbf{9}$, 11-13 [31]. Pulsed Q-band EPR spectroscopy was measured on $0.5 \mathrm{mM} \mathrm{D}_{2} \mathrm{SO}_{4}$ solution of complexes 9, 11, 23 and 24 because they have the same ligand Pc. $T_{1}$ for those complexes were found to be in the order of $\mathbf{2 3}(0.69 \mathrm{~ms})<\mathbf{2 4}(11.1 \mathrm{~ms})<\mathbf{1 1}(103 \mathrm{~ms})<\mathbf{9}(2.4 \mathrm{~s})$ at $7 \mathrm{~K}$, which is in accord with the conclusion that smaller SOC effects generate longer spin-lattice relaxation times [33,61]. The $T_{2}$ values at $7 \mathrm{~K}$ are $22 \mu \mathrm{s}, 41 \mu \mathrm{s}, 14 \mu \mathrm{s}$ and $9.44 \mu \mathrm{s}$ for $\mathbf{9}, \mathbf{1 1}, 23$ and $\mathbf{2 4}$, respectively. 


\section{Single-Ion Magnetic Molecules with Single 4f Spins}

Lanthanide-based SIMs have been intensively investigated for more than 10 years and have achieved significant progress in information storage and spintronic aspects, such as, (i) high magnetic hysteresis temperature (30 K) [62]; (ii) high magnetic anisotropic energy barrier (1000 K) [63]; and (iii) surface deposition of molecular magnets without changing the original magnetism [64-67]. In contrast, the attempts of using lanthanide-based SIMs as spin qubits have just begun $[8,9,68,69]$. Examples we will discuss include some lanthanide polyoxometalates [70-73], the famous $\mathrm{TbPc}_{2}[39,40,74,75]$ and one Yb complex [76], see also Table 4.

Table 4. 4f based single-ion spin qubits.

\begin{tabular}{cccccc}
\hline Complex & $\boldsymbol{T}_{\mathbf{1}} / \boldsymbol{\mu s}$ & $\boldsymbol{T}_{\mathbf{2}} / \boldsymbol{\mu s} \mathbf{s}^{\mathbf{a}}$ & $\boldsymbol{T}_{\mathbf{2}} / \boldsymbol{\mu} \mathbf{s}^{\mathbf{b}}$ & $\boldsymbol{T}_{\mathbf{R}} / \mathbf{K}^{\mathbf{c}}$ & $\boldsymbol{R e f}$ \\
\hline$\left[\mathrm{Gd}\left(\mathrm{P}_{5} \mathrm{~W}_{30} \mathrm{O}_{110}\right)\right] \mathrm{K}_{14} \mathrm{nH}_{2} \mathrm{O}(\mathbf{2 5})$ & $1.6(6 \mathrm{~K})$ & $0.41(6 \mathrm{~K})$ & - & 5 & {$[70,71]$} \\
{$\left[\mathrm{Ho}\left(\mathrm{W}_{5} \mathrm{O}_{18} \mathrm{P}\right)_{2}\right]^{9-}(\mathbf{2 6})$} & $20(5 \mathrm{~K})$ & - & $8.4(5 \mathrm{~K})$ & - & {$[73]$} \\
$\mathrm{TbPc}_{2}(\mathbf{2 7})$ & - & - & $64(40 \mathrm{mK})$ & 0.04 & {$[40]$} \\
$\mathrm{Yb}(\text { trensal })_{3}(\mathbf{2 8})$ & $0.2(20 \mathrm{~K})$ & $0.17(15 \mathrm{~K})$ & $0.53(2.7 \mathrm{~K})$ & 5 & {$[76]$} \\
\hline
\end{tabular}

${ }^{a}$ Reported $T_{2}$ values at the highest temperatures; ${ }^{b}$ Best $T_{2}$ values; ${ }^{\mathrm{c}}$ Reported temperatures for Rabi oscillations.

\subsection{Single-Lanthanide Polyoxometalates as Spin Qubits}

Though the magnetism of free Gd(III) ion is very isotropic, $\mathrm{Gd}(\mathrm{III})$ complexes with special coordination environments can behave as single-molecule magnets at very low temperatures [70,77]. The tungsten-based polyoxometalates are such ligand beds for $\mathrm{Gd}(\mathrm{III})$ ions. Compounds $\left[\mathrm{Gd}\left(\mathrm{P}_{5} \mathrm{~W}_{30} \mathrm{O}_{110}\right)\right]^{12-}(25)$ and $\left[\mathrm{Gd}\left(\mathrm{W}_{5} \mathrm{O}_{18} \mathrm{P}\right)_{2}\right]^{9-}\left(\mathrm{GdW}_{10}\right)$ (Figure 12) show slow magnetic relaxation behaviors below $300 \mathrm{mK}$. The relaxation times for $\mathrm{GdW}_{10}$ follow the activated behavior with an energy barrier of $2.2 \mathrm{~K}$. However, for 25 , relaxation times depend weakly on temperature and show a strong deviation from the expected thermally activated behavior. Qualitative fitting of their EPR data proves that the magnetic anisotropy is raised by mixing ground and excited states, resulting in easy-axial magnetic anisotropy for $\mathrm{GdW}_{10}$ and an easy-plane magnetic anisotropy for $\mathbf{2 5}$. This difference further influences their application as spin qubits. Pulsed X-band EPR experiments give coherence figure of merit $Q_{M}>50$ for 25 with observation of Rabi oscillations at $5 \mathrm{~K}$, proving the possibility of spin qubits [71].

Another single-lanthanide polyoxometalate for spin qubit is the complex $\left[\mathrm{Ho}\left(\mathrm{W}_{5} \mathrm{O}_{18} \mathrm{P}\right)_{2}\right]^{9-}$ (26) [72,73], an analogy of $\mathrm{GdW}_{10}$ with a different lanthanide center. The Ho(III) ion is encapsulated between two $\mathrm{W}_{5} \mathrm{O}_{18}$ POM units that provide a square-antiprismatic coordination geometry with $D_{4 d}$ symmetry (Figure 13a). By high-frequency and X-band EPR measurements, the hyperfine-split $m_{J}= \pm 4$ ground states can be observed (Figure 13b). The tunneling gap is about $9 \mathrm{GHz}$, which make 26 suitable for spin qubits [72]. The dilution study of $\mathbf{2 6}$ was carried out on $\mathrm{Na}_{9}\left[\mathrm{Ho}_{x} \mathrm{Y}_{(1-x)}\left(\mathrm{W}_{5} \mathrm{O}_{18}\right)_{2}\right] \cdot n \mathrm{H}_{2} \mathrm{O}$, where $x$ ranges from 0.001 to 0.25 [73]. For $x=0.001$, a long $T_{2}$ of $8.4 \mu \mathrm{s}$ was detected together with $T_{1}$ of $20 \mu \mathrm{s}$ at $5 \mathrm{~K}$ (Figure 13c). Interestingly, $T_{2}$ remains at higher concentrations for a long period (about $8.0 \mu \mathrm{s}$ for $x=0.01$ and $0.7 \mu \mathrm{s}$ for $x=0.1$ ) at $5 \mathrm{~K}$. The main contribution to those narrow resonances is found to be a Gaussian distribution in the $B_{4}^{4}$ parameter. Thus, by exploiting optimal operating points or atomic clock transitions between hyperfine states, quantum coherence times could be significantly protected regardless of spin concentrations [73]. 
a

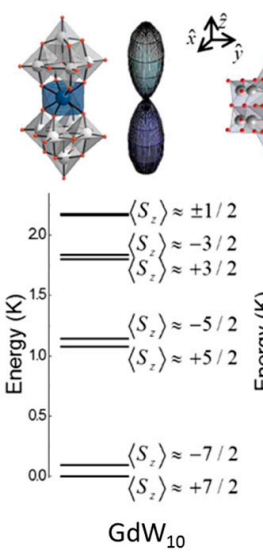

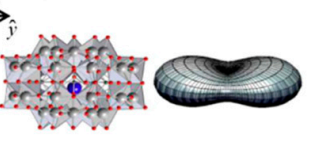

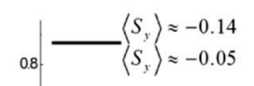

$\widehat{\underline{x}}^{0.6}=\left\langle S_{y}\right\rangle \approx-0.69$

${ }_{0.2} \vec{\omega}^{0.4}=\begin{aligned} & \left\langle S_{y}\right\rangle \approx+0.64 \\ & \left\langle S_{y}\right\rangle \approx-1.95 \\ & \left\langle S_{y}\right\rangle \approx+2.18 \equiv|1\rangle \\ & \left\langle S_{y}\right\rangle \approx-3.44\end{aligned}$

0.0

$\mathrm{GdW}_{30}$ b
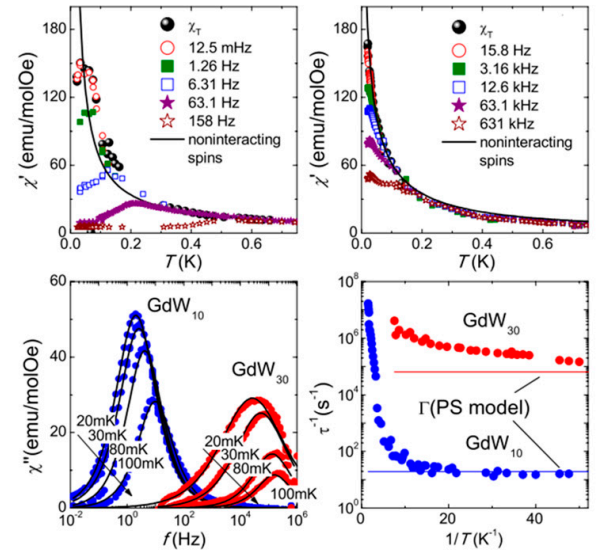

C
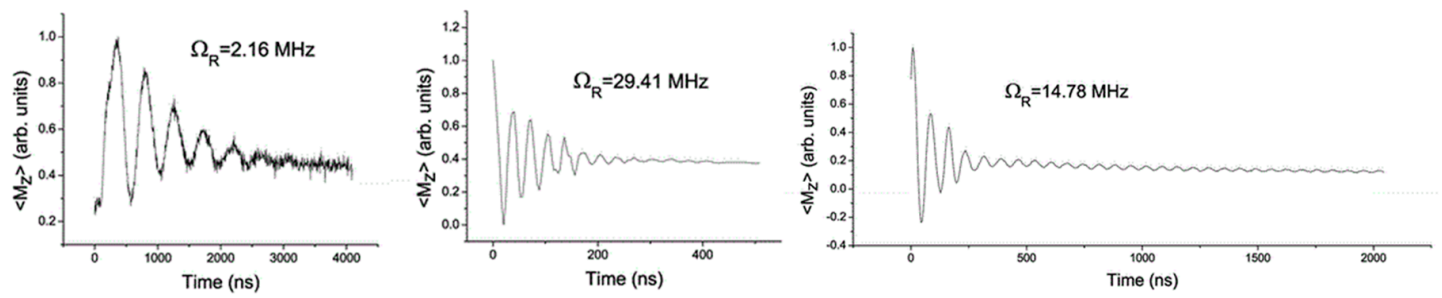

Figure 12. (a) Molecular structures of $\mathrm{GdW}_{10}$ and 25; energy levels of $\mathrm{GdW}_{10}$ and 25 for $H_{\mathrm{dc}}=10$ mT; (b) Ac magnetic susceptibility measured at indicated temperatures and the relaxation times for $\mathrm{GdW}_{10}$ and 25 (adapted with permission from [70]); (c) Rabi oscillations for $\mathbf{2 5}$ at indicated microwave (adapted with permission from [71].
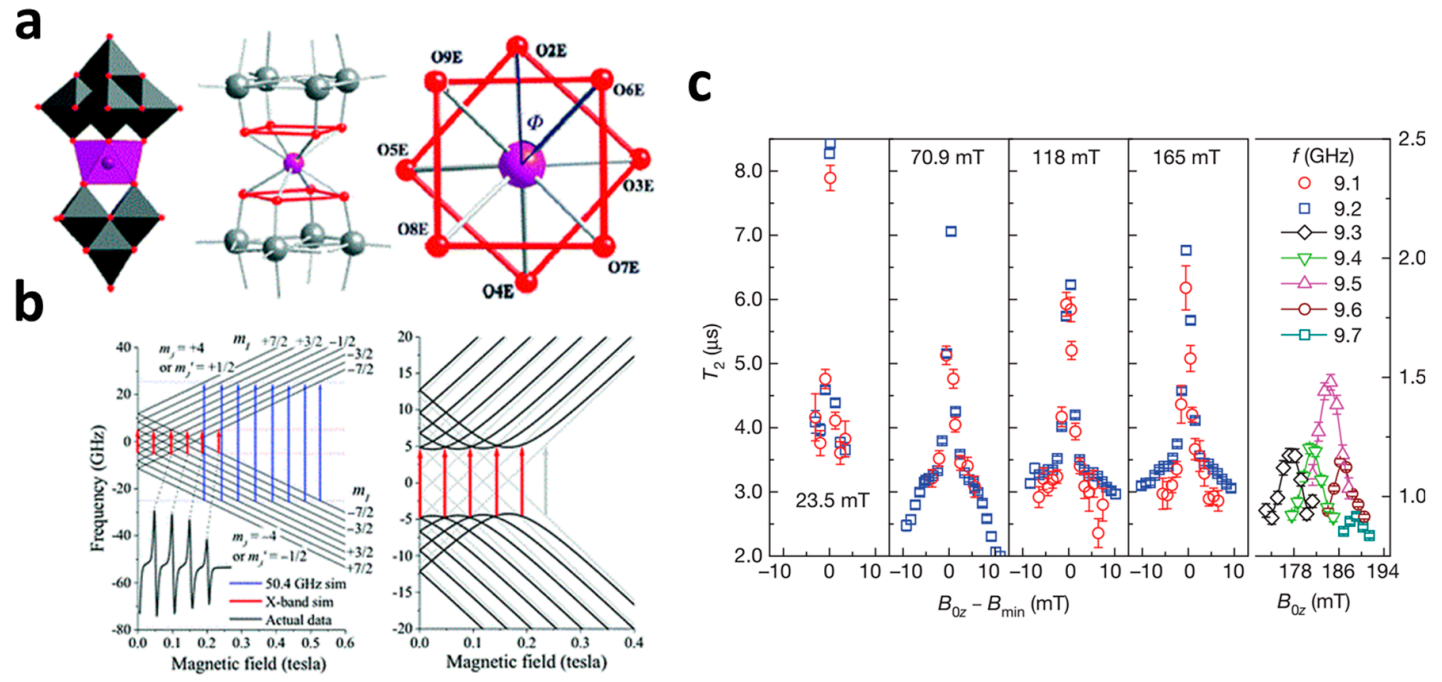

Figure 13. (a) Polyhedral representation, molecular structures and separate view along the axial z-direction of $\mathbf{2 6}$ (adapted with permission from [72]); (b) Zeeman diagrams corresponding to the hyperfine-split $m_{J}= \pm 4$ ground states (adapted with permission from [72]); (c) Field-swept $T_{2}$ recorded at $5.0 \mathrm{~K}$ at indicated frequencies and fields for $\mathrm{Na}_{9}\left[\mathrm{Ho}_{x} \mathrm{Y}_{(1-x)}\left(\mathrm{W}_{5} \mathrm{O}_{18}\right)_{2}\right] \cdot n \mathrm{H}_{2} \mathrm{O}(x=0.001)$ (adapted with permission from [73]).

\subsection{Tb(III) Based Nuclear-Spin Qubits}

$\mathrm{TbPc}_{2} 27$, one of the high-performance SIMs, has also been identified as one promising qubit for several reasons $[39,40,74,75]$. (I) The synthesis of this complex is facile and controllable with various 
functional groups [78]; (II) The magnetic properties are robust, which can be retained after sublimation at $820 \mathrm{~K}$ on a copper surface [64]; (III) The two Pc ligands have a conjugated p system, which can easily conduct electrons; while the valence state for $\mathrm{Tb}(\mathrm{III})$ is very stable, so that the current flow does not damage the complex [39]; (IV) The flat Pc ligands help graft the complexes on various surfaces, including gold, carbon nanotube, graphite, etc. With all these characteristics, it is possible to make 27 a spintronic devices (Figure 14a). Magnetic studies of 27 reveal a strong uniaxial magnetic anisotropy with ground $J=6$ state separated from the excited states by an energy gap of more than $400 \mathrm{~cm}^{-1}[1,79]$. With the nuclear spin $I=3 / 2$, strong hyperfine coupling between the ground state and the nuclear spin makes the ground states split into four sub-states (Figure 14b), which can be functionalized as quantum microstates. The coherence time $T_{2}$ for 27 is about $64.0 \mu \mathrm{s}$ with isotope-dependent relaxation times, while $T_{1}$ is more than $10 \mathrm{~s}$. Moreover, Rabi oscillations are observed (Figure 14c,d) [40].
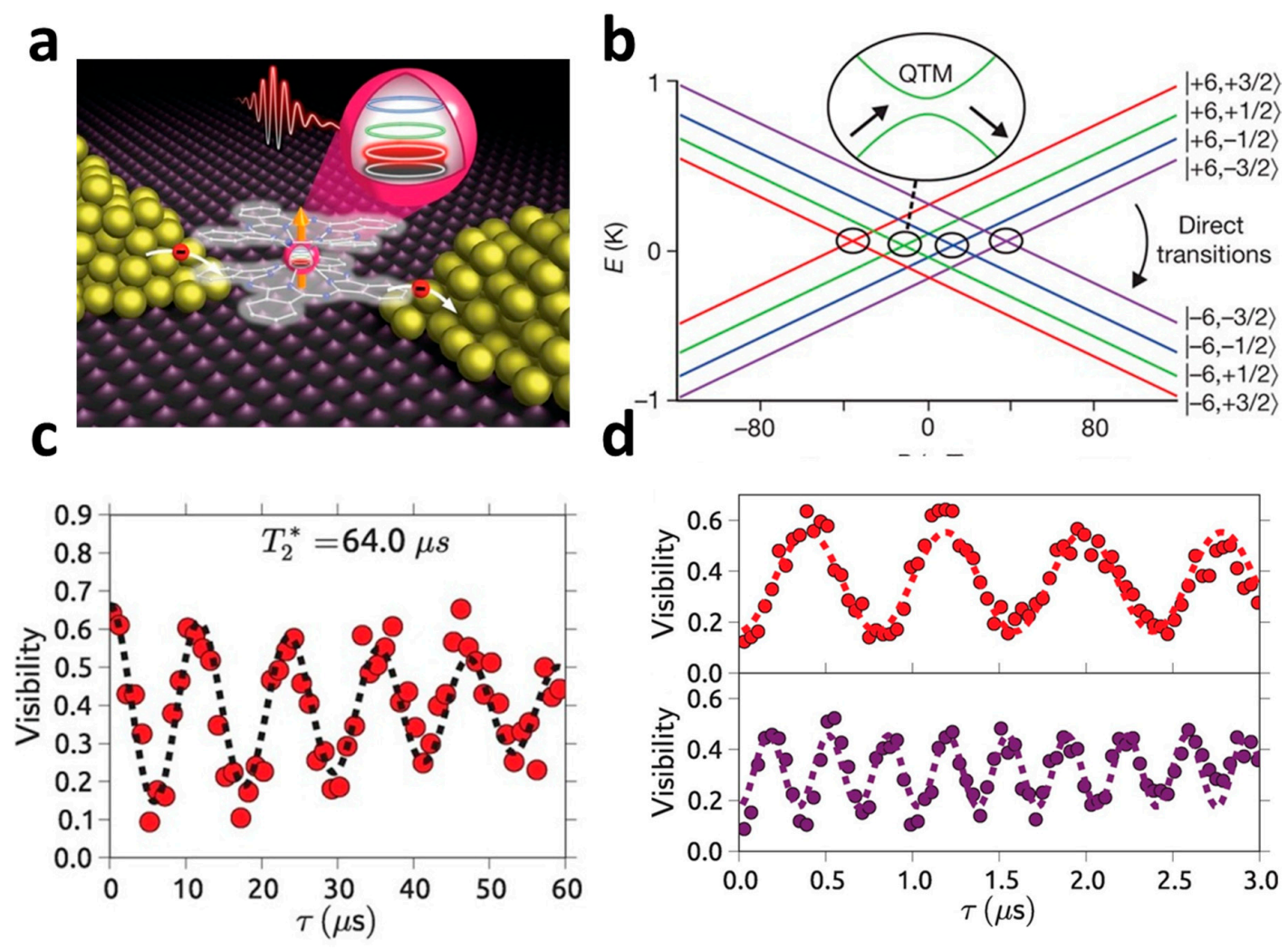

Figure 14. (a) Artist's view of a nuclear spin qubit transistor based on a single 27 molecule. The four anisotropic nuclear spin states of the $\mathrm{Tb}^{3+}$ (colored circles) can be manipulated by an electric field pulse (adapted with permission from [40]); (b) The two ground states are each split into four different sub-states owing to the hyperfine coupling with the nuclear spin $(I=3 / 2)$. Colored lines denote the $I_{\mathrm{Z}}$ components: purple, $-3 / 2$; blue, $-1 / 2$; green, $1 / 2$; and red, 3/2. Two processes are responsible for the magnetization reversal (adapted with permission from [39]); (c) Ramsey interference fringes obtained by repeating time-dependent external magnetic field and pulse sequence for 100 times at $40 \mathrm{mK}$ (adapted with permission from [40]); (d) Rabi oscillations obtained by repeating the above sequence in (c) for 100 times at $40 \mathrm{mK}$ (adapted with permission from [40]).

\subsection{Yb(III) Based Spin Qubits}

For $\mathrm{Yb}(\mathrm{III})$ ions, the ground state is a Kramers doublet with $J=7 / 2$, which can be approximated as an effective spin- $1 / 2$ system at low temperatures [76]. Its isotopes include $I=1 / 2\left({ }^{171} \mathrm{Yb}\right), I=$ $5 / 2\left({ }^{173} \mathrm{Yb}\right)$ and 0 for the others. To detect the quantum coherence of $\mathrm{Yb}$ (trensal) $28\left(\mathrm{H}_{3}\right.$ trensal $=$ $2,2^{\prime}, 2^{\prime \prime}$-tris(salicylideneimino)triethylamine), sample of $7 \% 28$ in diamagnetic $\mathrm{Lu}$ (trensal) was prepared for EPR measurements (Figure 15a) [76]. Fitting the echo-detected field-swept (EDFS) X-band pulsed 
EPR spectrum gave both spin-lattice relaxation times $T_{1}$ and quantum coherence times $T_{2}$ (Figure 15c). The $T_{1}$ values are in accord with ac susceptibility studies on bulk 28, which exhibits strong temperature dependence behavior and can be described by a power law [80]. On the contrary, $T_{2}$ is weakly temperature dependent and reaches $0.5 \mu \mathrm{s}$ at $3 \mathrm{~K}$. Clear oscillatory behavior was observed at $5 \mathrm{~K}$ (Figure 15d). The peak widths show little difference for all isotopes, but for the damping, the oscillations at " $I=0$ lines" are much stronger than other isotopes. Besides, more than 70 Rabi oscillations can be observed extending to $4 \mu \mathrm{s}$. Together with the coherence figure of merit $Q_{M}$ of about 40, complex 28 is an excellent candidate for QIP.
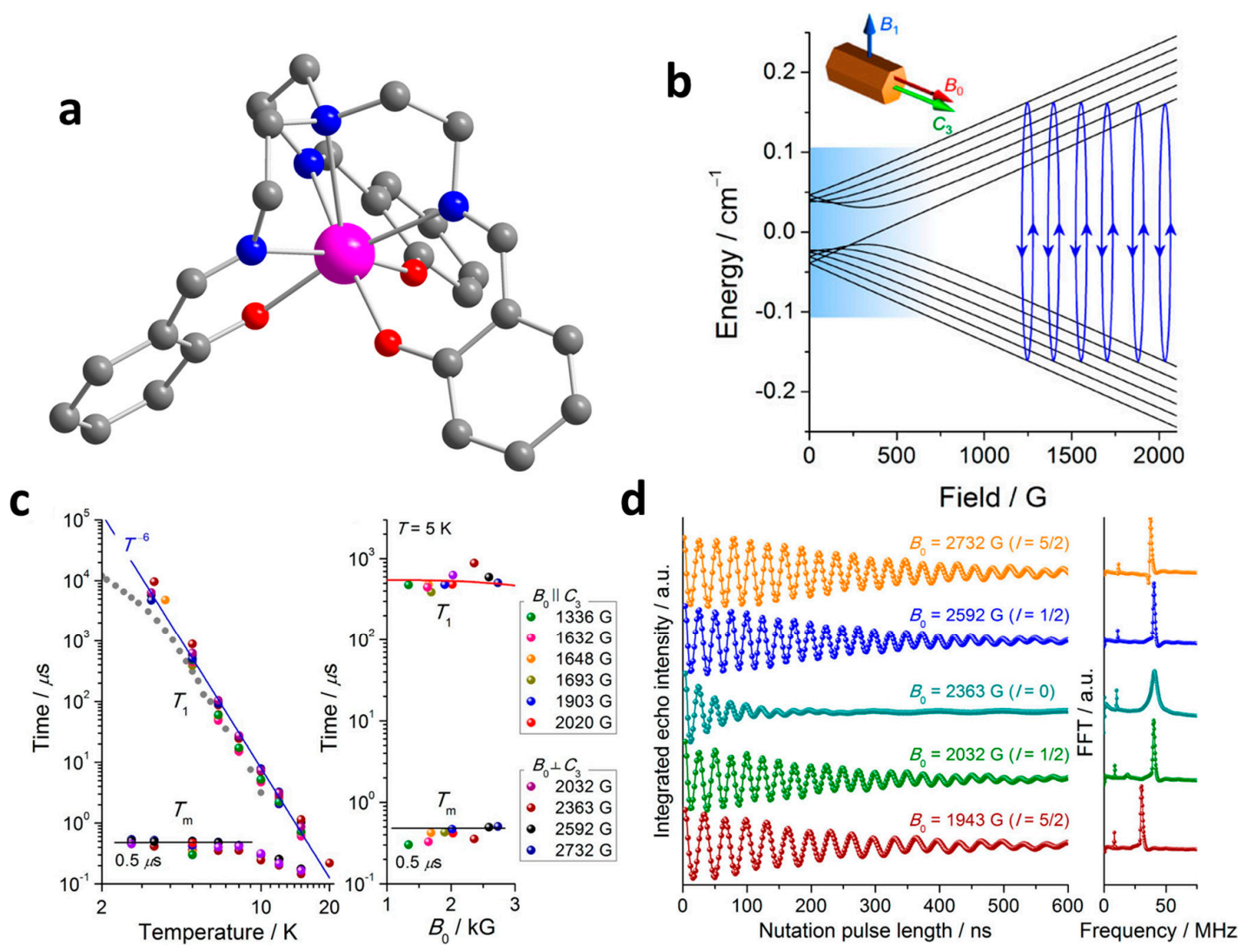

Figure 15. (a) Molecular structure of $\mathrm{Yb}$ (trensal) in 28 (Pink, $\mathrm{Yb}$; red, O; blue, N; gray, C, hydrogen atoms are omitted for clarity); (b) Zeeman diagram of the $I=5 / 2$ isotope; (c) Temperature dependence of $T_{1}$ and $T_{2}$ determined by pulsed EPR for $7 \% 28$ in Lu(trensal); (d) Echo intensity, proportional to the expectation value $\left\langle S_{\mathrm{z}}\right\rangle$, as a function of the length of the nutation pulse $\left(t_{\mathrm{p}}\right)$ at selected field positions at $T=5 \mathrm{~K}$ (microwave attenuation $=3 \mathrm{~dB}$ ) and its corresponding Fourier transforms (adapted with permission from [76]).

\subsection{Lanthanide-Doped Spin Qubits}

By doping lanthanide ions into some inorganic crystals, many solid-state qubits were found, despite that it is hard to control the environment of lanthanide ions [13,81-86]. Typical examples include doping $\mathrm{Er}(\mathrm{III})$ ions into $\mathrm{CaWO}_{4}$, which gives $\mathrm{Er}(\mathrm{III}): \mathrm{CaWO}_{4}$ with $\mathrm{T}_{2}$ of $50 \mu$ s at $2.5 \mathrm{~K}$ and $Q_{\mathrm{M}}$ of 1400 [13] and $\operatorname{Pr}(\mathrm{III}): \mathrm{Y}_{2} \mathrm{SiO}_{5}$ with long phase memory time of $82 \mathrm{~ms}$ [82]. Other lanthanide elements using a similar doping method include $\mathrm{Nd}(\mathrm{III})$ [84] and Eu(III) [86].

\section{Conclusions and Perspectives}

From the above analyses, we can see the practice of SIMs for spin qubits is still in its infancy, especially for lanthanide based SIMs, yet many exciting results have been achieved in the field. These 
include: (i) long quantum coherence times (e.g., complex 2 exhibits $T_{2}=657 \mu$ s at $7 \mathrm{~K}$; complex 10 exhibits $T_{2}=1 \mu \mathrm{s}$ for at room-temperature; while $T_{1}$ reaches $10 \mathrm{~s}$ for $\mathrm{TbPc}_{2}$ at low temperatures); (ii) Rabi oscillations are well observed in many well isolated molecules; (iii) electrically read-out of a single nuclear spin using a molecular spintronic device was achieved; (iv) chemical linkage for CNOT gate operations was demonstrated. Last but not least, the decoherence-structural correlation of SIMs is becoming clearer, which is extremely encouraging for chemists who are working on this field because this knowledge may help to design better spin qubits. The key points can be summarized as follows. Firstly, the quantum states must exist, which may arise from hyperfine coupling of the electron spin and nuclear spin or the spin orbital coupling with a proper energy gap (reasonably between 2 and $20 \mathrm{GHz}$ ). Secondly, the ligands, especially the atoms directly coordinated to the metal center, would significantly influence the electronic structure of the center ions. Nuclear spin free atoms are often favorable in this area, such as C and S. Besides, if there is an H atom in the ligands, deuteration often helps to protect the quantum coherence. Finally, the concentration, which is often adjusted by solvents or diamagnetic analogy, is also crucial. Nuclear spin free solvents (e.g., $\mathrm{CS}_{2}$ ) can effectively enhance the coherence time. Since all these factors are chemically controllable, it is very encouraging for chemists to design high performance single spin qubits based on the toolbox of synthetic chemistry. Only if the quantum coherence time is long enough at room temperature can the realization of QIP for daily usage be expected.

Acknowledgments: This work was supported by "973 project" (2012CB619402), NSFC (21473129, 21503155, IRT13034 and 21620102002), “National Young 1000-Plan" program, Fundamental Research Funds for Central Universities and Wuhan National High Magnetic Field Center (2015KF06).

Conflicts of Interest: The authors declare no conflict of interest.

\section{References}

1. Ishikawa, N.; Sugita, M.; Ishikawa, T.; Koshihara, S.Y.; Kaizu, Y. Lanthanide double-decker complexes functioning as magnets at the single-molecular level. J. Am. Chem. Soc. 2003, 125, 8694-8695. [CrossRef] [PubMed]

2. Rinehart, J.D.; Long, J.R. Exploiting single-ion anisotropy in the design of f-element single-molecule magnets. Chem. Sci. 2011, 2, 2078-2085. [CrossRef]

3. Woodruff, D.N.; Winpenny, R.E.P.; Layfield, R.A. Lanthanide Single-Molecule Magnets. Chem. Rev. 2013, 113, 5110-5148. [CrossRef] [PubMed]

4. Feltham, H.L.C.; Brooker, S. Review of purely $4 f$ and mixed-metal nd-4f single-molecule magnets containing only one lanthanide ion. Coord. Chem. Rev. 2014, 276, 1-33. [CrossRef]

5. Craig, G.A.; Murrie, M. 3d single-ion magnets. Chem. Soc. Rev. 2015, 44, 2135-2147. [CrossRef] [PubMed]

6. Gatteschi, D.; Sessoli, R.; Villain, J. Molecular Nanomagnets; Oxford University Press: Oxford, UK, 2006.

7. Benelli, C.; Gatteschi, D. Introduction to Molecular Magnetism: From Transition Metals to Lanthanides; Wiley-VCH Verlag GmbH \& Co.: Weinheim, Germany, 2015.

8. Gao, S. Molecular Nanomagnets and Related Phenomena; Springer: New York, NY, USA, 2015; Volume 164.

9. Layfield, R.A.; Murugesu, M. Lanthanides and Actinides in Molecular Magnetism; Wiley-VCH: Weinheim, Germany, 2015.

10. Bennett, C.H.; DiVincenzo, D.P. Quantum information and computation. Nature 2000, 404, $247-255$. [CrossRef] [PubMed]

11. Nielsen, M.A.; Chuang, I.L. Quantum Computation and Quantum Information; Cambridge University Press: Cambridge, UK, 2010.

12. Aromi, G.; Aguila, D.; Gamez, P.; Luis, F.; Roubeau, O. Design of magnetic coordination complexes for quantum computing. Chem. Soc. Rev. 2012, 41, 537-546. [CrossRef] [PubMed]

13. Bertaina, S.; Gambarelli, S.; Tkachuk, A.; Kurkin, I.N.; Malkin, B.; Stepanov, A.; Barbara, B. Rare-earth solid-state qubits. Nat. Nanotechnol. 2007, 2, 39-42. [CrossRef] [PubMed]

14. Ladd, T.D.; Jelezko, F.; Laflamme, R.; Nakamura, Y.; Monroe, C.; O Brien, J.L. Quantum computers. Nature 2010, 464, 45-53. [CrossRef] [PubMed] 
15. Cirac, J.I.; Zoller, P. Quantum computations with cold trapped ions. Phys. Rev. Lett. 1995, 74, 4091-4094. [CrossRef] [PubMed]

16. Monroe, C.; Kim, J. Scaling the ion trap quantum processor. Science 2013, 339, 1164-1169. [CrossRef] [PubMed]

17. Knill, E.; Laflamme, R.; Milburn, G.J. A scheme for efficient quantum computation with linear optics. Nature 2001, 409, 46-52. [CrossRef] [PubMed]

18. Gershenfeld, N.A.; Chuang, I.L. Bulk spin-resonance quantum computation. Science 1997, 275, 350-356. [CrossRef] [PubMed]

19. Clarke, J.; Wilhelm, F.K. Superconducting quantum bits. Nature 2008, 453, 1031-1042. [CrossRef] [PubMed]

20. Devoret, M.H.; Schoelkopf, R.J. Superconducting circuits for quantum information: An outlook. Science 2013, 339, 1169-1174. [CrossRef] [PubMed]

21. Loss, D.; DiVincenzo, D.P. Quantum computation with quantum dots. Phys. Rev. A 1998, 57, 120. [CrossRef]

22. Awschalom, D.D.; Bassett, L.C.; Dzurak, A.S.; Hu, E.L.; Petta, J.R. Quantum spintronics: Engineering and manipulating atom-like spins in semiconductors. Science 2013, 339, 1174-1179. [CrossRef] [PubMed]

23. Hanson, R.; Awschalom, D.D. Coherent manipulation of single spins in semiconductors. Nature 2008, 453, 1043-1049. [CrossRef] [PubMed]

24. Sato, K.; Nakazawa, S.; Rahimi, R.; Ise, T.; Nishida, S.; Yoshino, T.; Mori, N.; Toyota, K.; Shiomi, D.; Yakiyama, Y.; et al. Molecular electron-spin quantum computers and quantum information processing: Pulse-based electron magnetic resonance spin technology applied to matter spin-qubits. J. Mater. Chem. 2009, 19, 3739-3754. [CrossRef]

25. Luis, F.; Repollés, A.; Martínez-Pérez, M.J.; Aguilà, D.; Roubeau, O.; Zueco, D.; Alonso, P.J.; Evangelisti, M.; Camón, A.; Sesé, J. Molecular prototypes for spin-based CNOT and SWAP quantum gates. Phys. Rev. Lett. 2011, 107, 117203. [CrossRef] [PubMed]

26. Lehmann, J.; Gaita-Ari Nmacr, A.; Coronado, E.; Loss, D. Spin qubits with electrically gated polyoxometalate molecules. Nat. Nanotechnol. 2007, 2, 312-317. [CrossRef] [PubMed]

27. Leuenberger, M.N.; Loss, D. Quantum computing in molecular magnets. Nature 2001, 410, 789-793. [CrossRef] [PubMed]

28. Ardavan, A.; Rival, O.; Morton, J.J.; Blundell, S.J.; Tyryshkin, A.M.; Timco, G.A.; Winpenny, R.E. Will spin-relaxation times in molecular magnets permit quantum information processing? Phys. Rev. Lett. 2007, 98, 057201. [CrossRef] [PubMed]

29. Wedge, C.J.; Timco, G.A.; Spielberg, E.T.; George, R.E.; Tuna, F.; Rigby, S.; McInnes, E.; Winpenny, R.; Blundell, S.J.; Ardavan, A. Chemical engineering of molecular qubits. Phys. Rev. Lett. 2012, 108, 107204. [CrossRef] [PubMed]

30. Kaminski, D.; Webber, A.L.; Wedge, C.J.; Liu, J.; Timco, G.A.; Vitorica-Yrezabal, I.J.; McInnes, E.J.; Winpenny, R.E.; Ardavan, A. Quantum spin coherence in halogen-modified $\mathrm{Cr}_{7} \mathrm{Ni}$ molecular nanomagnets. Phys. Rev. B 2014, 90, 184419. [CrossRef]

31. Bader, K.; Winkler, M.; van Slageren, J. Tuning of molecular qubits: Very long coherence and spin-lattice relaxation times. Chem. Commun. 2016, 52, 3623-3626. [CrossRef] [PubMed]

32. Fielding, A.J.; Fox, S.; Millhauser, G.L.; Chattopadhyay, M.; Kroneck, P.M.; Fritz, G.; Eaton, G.R.; Eaton, S.S. Electron spin relaxation of copper (II) complexes in glassy solution between 10 and 120 K. J. Magn. Reson. 2006, 179, 92-104. [CrossRef] [PubMed]

33. Graham, M.J.; Zadrozny, J.M.; Shiddiq, M.; Anderson, J.S.; Fataftah, M.S.; Hill, S.; Freedman, D.E. Influence of Electronic Spin and Spin-Orbit Coupling on Decoherence in Mononuclear Transition Metal Complexes. J. Am. Chem. Soc. 2014, 136, 7623-7626. [CrossRef] [PubMed]

34. Repollés Rabinad, A.M. Quantum Computing with Molecular Magnets; Prensas de la Universidad de Zaragoza: Zaragoza, Spain, 2016; Volume 131.

35. Timco, G.A.; Carretta, S.; Troiani, F.; Tuna, F.; Pritchard, R.J.; Muryn, C.A.; McInnes, E.J.; Ghirri, A.; Candini, A.; Santini, P. Engineering the coupling between molecular spin qubits by coordination chemistry. Nat. Nanotechnol. 2009, 4, 173-178. [CrossRef] [PubMed]

36. Lan, Y.; Klyatskaya, S.; Ruben, M.; Fuhr, O.; Wernsdorfer, W.; Candini, A.; Corradini, V.; Rizzini, A.L.; Del Pennino, U.; Troiani, F. Magnetic interplay between two different lanthanides in a tris-phthalocyaninato complex: A viable synthetic route and detailed investigation in the bulk and on the surface. J. Mater. Chem. C 2015, 3, 9794-9801. [CrossRef] 
37. Aguilà, D.; Barrios, L.A.; Velasco, V.; Roubeau, O.; Repollés, A.; Alonso, P.J.; Sesé, J.; Teat, S.J.; Luis, F.; Aromí, G. Heterodimetallic [LnLn'] lanthanide complexes: Toward a chemical design of two-qubit molecular spin quantum gates. J. Am. Chem. Soc. 2014, 136, 14215-14222. [CrossRef] [PubMed]

38. Ferrando-Soria, J.; Pineda, E.M.; Chiesa, A.; Fernandez, A.; Magee, S.A.; Carretta, S.; Santini, P.; Vitorica-Yrezabal, I.J.; Tuna, F.; Timco, G.A. A modular design of molecular qubits to implement universal quantum gates. Nat. Commun. 2016, 7, 11377. [CrossRef] [PubMed]

39. Vincent, R.; Klyatskaya, S.; Ruben, M.; Wernsdorfer, W.; Balestro, F. Electronic read-out of a single nuclear spin using a molecular spin transistor. Nature 2012, 488, 357-360. [CrossRef] [PubMed]

40. Thiele, S.; Balestro, F.; Ballou, R.; Klyatskaya, S.; Ruben, M.; Wernsdorfer, W. Electrically driven nuclear spin resonance in single-molecule magnets. Science 2014, 344, 1135-1138. [CrossRef] [PubMed]

41. Zadrozny, J.M.; Niklas, J.; Poluektov, O.G.; Freedman, D.E. Multiple Quantum Coherences from Hyperfine Transitions in a Vanadium(IV) Complex. J. Am. Chem. Soc. 2014, 136, 15841-15844. [CrossRef] [PubMed]

42. Zadrozny, J.M.; Niklas, J.; Poluektov, O.G.; Freedman, D.E. Millisecond Coherence Time in a Tunable Molecular Electronic Spin Qubit. ACS Cent. Sci. 2015, 1, 488-492. [CrossRef] [PubMed]

43. Stanwix, P.L.; Pham, L.M.; Maze, J.R.; Le Sage, D.; Yeung, T.K.; Cappellaro, P.; Hemmer, P.R.; Yacoby, A.; Lukin, M.D.; Walsworth, R.L. Coherence of nitrogen-vacancy electronic spin ensembles in diamond. Phys. Rev. B 2010, 82, 201201. [CrossRef]

44. Koehl, W.F.; Buckley, B.B.; Heremans, F.J.; Calusine, G.; Awschalom, D.D. Room temperature coherent control of defect spin qubits in silicon carbide. Nature 2011, 479, 84-87. [CrossRef] [PubMed]

45. Tesi, L.; Lucaccini, E.; Cimatti, I.; Perfetti, M.; Mannini, M.; Atzori, M.; Morra, E.; Chiesa, M.; Caneschi, A.; Sorace, L. Quantum coherence in a processable vanadyl complex: New tools for the search of molecular spin qubits. Chem. Sci. 2016, 7, 2074-2083. [CrossRef]

46. Tesi, L.; Lunghi, A.; Atzori, M.; Lucaccini, E.; Sorace, L.; Totti, F.; Sessoli, R. Giant spin-phonon bottleneck effects in evaporable vanadyl-based molecules with long spin coherence. Dalton. Trans. 2016, 45, 16635-16643. [CrossRef] [PubMed]

47. Atzori, M.; Morra, E.; Tesi, L.; Albino, A.; Chiesa, M.; Sorace, L.; Sessoli, R. Quantum Coherence Times Enhancement in Vanadium (IV)-based Potential Molecular Qubits: The Key Role of the Vanadyl Moiety. J. Am. Chem. Soc. 2016, 138, 11234-11244. [CrossRef] [PubMed]

48. Atzori, M.; Tesi, L.; Morra, E.; Chiesa, M.; Sorace, L.; Sessoli, R. Room-Temperature Quantum Coherence and Rabi Oscillations in Vanadyl Phthalocyanine: Toward Multifunctional Molecular Spin Qubits. J. Am. Chem. Soc. 2016, 138, 2154-2157. [CrossRef] [PubMed]

49. Warner, M.; Din, S.; Tupitsyn, I.S.; Morley, G.W.; Stoneham, A.M.; Gardener, J.A.; Wu, Z.; Fisher, A.J.; Heutz, S.; Kay, C.W. Potential for spin-based information processing in a thin-film molecular semiconductor. Nature 2013, 503, 504-508. [CrossRef] [PubMed]

50. Bader, K.; Dengler, D.; Lenz, S.; Endeward, B.; Jiang, S.; Neugebauer, P.; van Slageren, J. Room temperature quantum coherence in a potential molecular qubit. Nat. Commun. 2014, 5, 6304. [CrossRef] [PubMed]

51. Fataftah, M.S.; Zadrozny, J.M.; Coste, S.C.; Graham, M.J.; Rogers, D.M.; Freedman, D.E. Employing Forbidden Transitions as Qubits in a Nuclear Spin-Free Chromium Complex. J. Am. Chem. Soc. 2016, 138, 1344-1348. [CrossRef] [PubMed]

52. Mor, H.H.; Weihe, H.; Bendix, J. Fitting of EPR spectra: The importance of a flexible bandwidth. J. Magn. Reson. 2010, 207, 283-286.

53. Stamp, P.C.; Gaita-Arino, A. Spin-based quantum computers made by chemistry: Hows and whys. J. Mater. Chem. 2009, 19, 1718-1730. [CrossRef]

54. Morello, A.; Stamp, P.; Tupitsyn, I.S. Pairwise decoherence in coupled spin qubit networks. Phys. Rev. Lett. 2006, 97, 207206. [CrossRef] [PubMed]

55. Bertaina, S.; Gambarelli, S.; Mitra, T.; Tsukerblat, B.; Müller, A.; Barbara, B. Quantum oscillations in a molecular magnet. Nature 2008, 453, 203-206. [CrossRef] [PubMed]

56. Bendix, J.; Brorson, M.; Schaffer, C.E. Accurate empirical spin-orbit coupling parameters. zeta. nd for gaseous ndq transition metal ions. The parametrical multiplet term model. Inorg. Chem. 1993, 32, 2838-2849. [CrossRef]

57. Bendix, J.; Steenberg, P.; Søtofte, I. Isolation and molecular structure of hexacyanoruthenate (III). Inorg. Chem. 2003, 42, 4510-4512. [CrossRef] [PubMed] 
58. Albores, P.; Slep, L.D.; Baraldo, L.M.; Baggio, R.; Garland, M.T.; Rentschler, E. Crystal structure and electronic and magnetic properties of hexacyanoosmate (III). Inorg. Chem. 2006, 45, 2361-2363. [CrossRef] [PubMed]

59. Zadrozny, J.M.; Freedman, D.E. Qubit Control Limited by Spin-Lattice Relaxation in a Nuclear Spin-Free Iron (III) Complex. Inorg. Chem. 2015, 54, 12027-12031. [CrossRef] [PubMed]

60. Zadrozny, J.M.; Graham, M.J.; Krzyaniak, M.D.; Wasielewski, M.R.; Freedman, D.E. Unexpected suppression of spin-lattice relaxation via high magnetic field in a high-spin iron (III) complex. Chem. Commun. 2016, 52, 10175-10178. [CrossRef] [PubMed]

61. Du, J.; Eaton, G.R.; Eaton, S.S. Electron spin relaxation in vanadyl, copper (II), and silver (II) porphyrins in glassy solvents and doped solids. J. Magn. Reson. Ser. A 1996, 119, 240-246. [CrossRef]

62. Gupta, S.K.; Rajeshkumar, T.; Rajaraman, G.; Murugavel, R. An air-stable Dy (iii) single-ion magnet with high anisotropy barrier and blocking temperature. Chem. Sci. 2016, 7, 5181-5191. [CrossRef]

63. Liu, J.; Chen, Y.; Jia, J.; Liu, J.; Vieru, V.; Ungur, L.; Chibotaru, L.F.; Lan, Y.; Wernsdorfer, W.; Gao, S. A Stable Pentagonal-Bipyramidal Dy (III) Single-Ion Magnet with a Record Magnetization Reversal Barrier over 1000 K. J. Am. Chem. Soc. 2016, 138, 5441-5450. [CrossRef] [PubMed]

64. Stepanow, S.; Honolka, J.; Gambardella, P.; Vitali, L.; Abdurakhmanova, N.; Tseng, T.; Rauschenbach, S.; Tait, S.L.; Sessi, V.; Klyatskaya, S. Spin and orbital magnetic moment anisotropies of monodispersed bis (phthalocyaninato) terbium on a copper surface. J. Am. Chem. Soc. 2010, 132, 11900-11901. [CrossRef] [PubMed]

65. Margheriti, L.; Chiappe, D.; Mannini, M.; Car, P.E.; Sainctavit, P.; Arrio, M.A.; de Mongeot, F.B.; Cezar, J.C.; Piras, F.M.; Magnani, A. X-Ray Detected Magnetic Hysteresis of Thermally Evaporated Terbium Double-Decker Oriented Films. Adv. Mater. 2010, 22, 5488-5493. [CrossRef] [PubMed]

66. Gonidec, M.; Biagi, R.; Corradini, V.; Moro, F.; De Renzi, V.; Del Pennino, U.; Summa, D.; Muccioli, L.; Zannoni, C.; Amabilino, D.B. Surface supramolecular organization of a terbium (III) double-decker complex on graphite and its single molecule magnet behavior. J. Am. Chem. Soc. 2011, 133, 6603-6612. [CrossRef] [PubMed]

67. Mannini, M.; Bertani, F.; Tudisco, C.; Malavolti, L.; Poggini, L.; Misztal, K.; Menozzi, D.; Motta, A.; Otero, E.; Ohresser, P. Magnetic behaviour of $\mathrm{TbPc}_{2}$ single-molecule magnets chemically grafted on silicon surface. Nat. Commun. 2014, 5, 5582. [CrossRef] [PubMed]

68. Gaita-Ariño, A.; Prima-Garcia, H.; Cardona-Serra, S.; Escalera-Moreno, L.; Rosaleny, L.E.; Baldovi, J.J. Coherence and organisation in lanthanoid complexes: From single ion magnets to spin qubits. Inorg. Chem. Front. 2016, 3, 568-577. [CrossRef]

69. Clemente-Juan, J.M.; Coronado, E.; Gaita-Ariño, A. Magnetic polyoxometalates: From molecular magnetism to molecular spintronics and quantum computing. Chem. Soc. Rev. 2012, 41, 7464-7478. [CrossRef] [PubMed]

70. Martínez-Pérez, M.J.; Cardona-Serra, S.; Schlegel, C.; Moro, F.; Alonso, P.J.; Prima-García, H.; Clemente-Juan, J.M.; Evangelisti, M.; Gaita-Ariño, A.; Sesé, J. Gd-based single-ion magnets with tunable magnetic anisotropy: Molecular design of spin qubits. Phys. Rev. Lett. 2012, 108, 247213. [CrossRef] [PubMed]

71. Baldovi, J.J.; Cardona-Serra, S.; Clemente-Juan, J.M.; Coronado, E.; Gaita-Ariño, A.; Prima-Garcia, H. Coherent manipulation of spin qubits based on polyoxometalates: The case of the single ion magnet $\left[\mathrm{GdW}_{30} \mathrm{P}_{5} \mathrm{O}_{110}\right]^{14-}$. Chem. Commun. 2013, 49, 8922-8924. [CrossRef] [PubMed]

72. Ghosh, S.; Datta, S.; Friend, L.; Cardona-Serra, S.; Gaita-Ariño, A.; Coronado, E.; Hill, S. Multi-frequency EPR studies of a mononuclear holmium single-molecule magnet based on the polyoxometalate $\left[\mathrm{Ho}^{\mathrm{III}}\left(\mathrm{W}_{5} \mathrm{O}_{18}\right)_{2}\right]^{9-}$. Dalton. Trans. 2012, 41, 13697-13704. [CrossRef] [PubMed]

73. Shiddiq, M.; Komijani, D.; Duan, Y.; Gaita-Ariño, A.; Coronado, E.; Hill, S. Enhancing coherence in molecular spin qubits via atomic clock transitions. Nature 2016, 531, 348-351. [CrossRef] [PubMed]

74. Urdampilleta, M.; Klayatskaya, S.; Ruben, M.; Wernsdorfer, W. Magnetic Interaction between a Radical Spin and a Single-Molecule Magnet in a Molecular Spin-Valve. ACS Nano 2015, 9, 4458-4464. [CrossRef] [PubMed]

75. Urdampilleta, M.; Klyatskaya, S.; Cleuziou, J.; Ruben, M.; Wernsdorfer, W. Supramolecular spin valves. Nat. Mater. 2011, 10, 502-506. [CrossRef] [PubMed]

76. Pedersen, K.S.; Ariciu, A.; McAdams, S.; Weihe, H.; Bendix, J.; Tuna, F.; Piligkos, S. Toward Molecular $4 \mathrm{f}$ Single-Ion Magnet Qubits. J. Am. Chem. Soc. 2016, 138, 5801-5804. [CrossRef] [PubMed] 
77. Holmberg, R.J.; Ungur, L.; Korobkov, I.; Chibotaru, L.F.; Murugesu, M. Observation of unusual slow-relaxation of the magnetisation in a Gd-EDTA chelate. Dalton. Trans. 2015, 44, 20321-20325. [CrossRef] [PubMed]

78. Ganivet, C.R.; Ballesteros, B.; de la Torre, G.; Clemente Juan, J.M.; Coronado, E.; Torres, T. Influence of Peripheral Substitution on the Magnetic Behavior of Single-Ion Magnets Based on Homo-and Heteroleptic $\mathrm{Tb}^{\mathrm{III}}$ Bis (phthalocyaninate). Chem. Eur. J. 2013, 19, 1457-1465. [CrossRef] [PubMed]

79. Ishikawa, N.; Sugita, M.; Wernsdorfer, W. Quantum Tunneling of Magnetization in Lanthanide Single-Molecule Magnets: Bis (phthalocyaninato) terbium and Bis (phthalocyaninato) dysprosium Anions. Angew. Chem. Int. Ed. 2005, 44, 2931-2935. [CrossRef] [PubMed]

80. Pedersen, K.S.; Dreiser, J.; Weihe, H.; Sibille, R.; Johannesen, H.V.; Sørensen, M.A.; Nielsen, B.E.; Sigrist, M.; Mutka, H.; Rols, S. Design of single-molecule magnets: Insufficiency of the anisotropy barrier as the sole criterion. Inorg. Chem. 2015, 54, 7600-7606. [CrossRef] [PubMed]

81. Bertaina, S.; Shim, J.H.; Gambarelli, S.; Malkin, B.Z.; Barbara, B. Spin-orbit qubits of rare-earth-metal ions in axially symmetric crystal fields. Phys. Rev. Lett. 2009, 103. [CrossRef] [PubMed]

82. Fraval, E.; Sellars, M.J.; Longdell, J.J. Method of Extending Hyperfine Coherence Times in $\operatorname{Pr}^{3+}: \mathrm{Y}_{2} \mathrm{SiO}_{5}$. Phys. Rev. Lett. 2004, 92, 77601. [CrossRef] [PubMed]

83. Ohlsson, N.; Mohan, R.K.; Kröll, S. Quantum computer hardware based on rare-earth-ion-doped inorganic crystals. Opt. Commun. 2002, 201, 71-77. [CrossRef]

84. Longdell, J.J.; Sellars, M.J. Experimental demonstration of quantum-state tomography and qubit-qubit interactions for rare-earth-metal-ion-based solid-state qubits. Phys. Rev. A 2004, 69, 032307. [CrossRef]

85. Rippe, L.; Nilsson, M.; Kröll, S.; Klieber, R.; Suter, D. Experimental demonstration of efficient and selective population transfer and qubit distillation in a rare-earth-metal-ion-doped crystal. Phys. Rev. A 2005, 71, 062328. [CrossRef]

86. Fraval, E.; Sellars, M.J.; Longdell, J.J. Dynamic decoherence control of a solid-state nuclear-quadrupole qubit. Phys. Rev. Lett. 2005, 95, 030506. [CrossRef] [PubMed]

(C) 2016 by the authors; licensee MDPI, Basel, Switzerland. This article is an open access article distributed under the terms and conditions of the Creative Commons Attribution (CC-BY) license (http://creativecommons.org/licenses/by/4.0/). 